\title{
THE SUPPLY OF SINGLE-PHASE POWER FROM THREE-PHASE SYSTEMS.
}

\author{
By Professor Miles Walker, D.Sc.
}

(Paper first received 27 September, and in final form I5 November, I9I8; read before THE INSTITUTION 5 December, I9I8, before the North Midland Centre ro December, 19i8, before the ScotTish CenTRE 14 January, I9I9, and before the NORTh-WeStern CENTRE 28 January, I9I9.)

\section{Summary.}

The various methods of supplying single-phase power are considered under the five heads enumerated in the next column. Of these, No. (4) and No. (5) are dealt with in some detail. Under No. (4), phase balancers are divided into stationary and running balancers. A qualification is added to Steinmetz's statement on stationary balancers. It ${ }^{\circ}$ is shown that the elimination of the alternating component of the power does not necessarily bring about a "balance of the phases," as defined on page I II. The correct method of balancing the phases in the case of an electric furnace working at 0.7 power factor is developed for both chokecoil balancer and condenser balancer. Running balancers are classified under five sub-headings $(a)$ to $(e)$, page $\mathrm{I} 2$, according to the method used of overcoming the impedance drop in the windings. The graphic diagrams of the different types are given, and the merits and drawbacks of these balancers discussed.

Under head No. (5) a new type of balancing transformer is described. A calculation of a balancing transformer for feeding a $400-\mathrm{kw}$. electric furnace is worked out. The figures obtained on the tests of the machine at no load and at full load are given.

\section{Present Demand for Single-phase Power.}

The advantages of three-phase power distribution over the single-phase systems in vogue 25 years ago are so generally acknowledged, that a very large proportion of the electrical power stations of the world generate alternating current in three phases. There are, however, some purposes for which single-phase current is to be preferred, as, for instance, in highvoltage alternating-current traction systems. Here the single-phase trolley wire and resulting connections are so much simpler than the double trolley wire and the adjuncts of a polyphase motor, that some engineers prefer a single-phase system. The successful operation of this type of traction in different parts of the world has created a considerable demand for single-phase power.

Another purpose for which single-phase power is required at the present time is the operation of electric furnaces. There can be no doubt that, putting aside all considerations of convenience of electric supply, and looking at the objects to be attained merely from the metallurgical point of view, the single-phase furnace has much to recommend it. Nevertheless, on account of the great objections raised by the suppliers of electric power to the unbalancing effect of a single-phase load upon their three-phase systems, the polyphase furnace is in much more extensive use in this country than the single-phase furnace.

In view of the very extensive use that will be made of electric furnaces for steel manufacture in the future, it is important to see what can be done to minimize the objection of the suppliers of electric power to a single-phase load.

Methods of Obtaining Single-phase Power.

Where single-phase power must be supplied for any specific purpose, we have a considerable choice of methods of obtaining it.

(I) Single-phase generators driven by prime movers.

(2) Three-phase generators constructed so as to give single-phase power.

(3) Motor-generator sets.

(4) The taking of single-phase current direct from one of the phases of a three-phase supply system, and the use of a balancer for balancing the phases.

(5) A rotating balancing transformer, which absorbs the balanced three-phase power in one winding and supplies a single-phase load from an independent winding.

\section{(I) Single-Phase Generators Driven by Prime} Movers.

Where the single-phase load is near some source of mechanical power, such as a large steam generating station or a water-power, it is comparatively a simple matter to install single-phase generators that can be run independently of any other generators in the station. This has been done in the case of several single-phase traction systems; for instance, in the case of the New Haven and Hartford Railway, where special single-phase steam-turbine-driven generators supply the trolley wire direct at II,000 volts.

The main objections to the single-phase generator are the following: The cost for a given output is higher than for a three-phase generator; for instance, the cost of a 25 -cycle single-phase generator of $5,000-\mathrm{kw}$. capacity, running at I,500 r.B.m., would be about 30 per cent higher than that of a three-phase generator of the same characteristics. This is partly because the single-phase output from a given frame is less than the three-phase output, and partly because a single-phase generator must be provided with a very heavy and well-constructed amortisseur on the field magnet, the cost of which is a considerable item. Secondly, the efficiency of a single-phase generator is . 
considerably lower than that of a three-phase generator of the same rating. This is caused partly by the higher Gron losses due to the single-phase armature reaction, and partly by the loss in the amortisseur and the metal surrounding it. The actual percentage by which the efficiency is thus reduced cannot be stated without reference to particular machines, because so much depends upon the proportions of iron and copper and upon the details of the design. Looking through a number of quotations that have been made by a manufacturing firm, the author finds that it is not uncommon for the guaranteed efficiency of a large single-phase generator to be $I \frac{1}{2}$ to 2 per cent lower than that of a three-phase generator of the same general characteristics.

It is in general inconvenient to provide special single-phase generators to supply the load, especially when the load is some distance away from the power station.

\section{(2) Three-phase Generators Constructed so as to} Give Single-Phase Power.

Where the load is divided between a number of locomotives or a number of furnaces which are not started simultaneously, it is possible to divide the whole into two parts, putting one part on to one phase of a two-phase generator and the other part on to the other phase. It may be that such an arrangement gives a balance of load that is good enough for practical purposes; and if the generator is constructed with an amortisseur so as to take a single-phase load without injury, this arrangement is perfectly satisfactory: Similarly, three indépendent loads can be taken from a three-phase system.

Effect of single-phase load on a three-phase generator. -In this connection it is interesting to inquire how far the voltage of a three-phase generator is disturbed when a single-phase load is thrown on one phase. In Appendix I will be found the grapbic construction for finding the voltage change in each phase when a single-phase load is thrown on one phase of a threephase generator. The figures obtained on a test of a generator are shown to agree very closely with the theoretical figures; and it is established that if the single-phase load (even of low power factor) does not exceed 20 per cent of the normal three-phase load the disturbance to the voltage is inconsiderable. An instance of this kind is found at Bradford, where single-phase furnaces of $400-\mathrm{kw}$. capacity are thrown on and off three-phase mains without causing a noticeable unbalancing of the voltages.

Single-phase armature reaction.-The ratio of the field ampere-turns on single-phase short-circuit to the field ampere-turns on three-phase short-circuit is also given in Appertix I. This is in the neighbourhood of $\rho .7$, but depends upon the pole arc and the efficiency of the amortisseur.

\section{(3) Motor-Generator Sets.}

In some cases where power companies have refused to connect a single-phase load on to their systems, - motor-generators have been installed. A motor- generator for this purpose may consist of an induction motor direct connected to a single-phase generator or a synchronous motor may be used to drive the single-phase generator, and in this case the set may be used for improving the power factor of the system by over-exciting the synchronous motor. For general convenience of operation this method is entirely satisfactory: the consumer has complete control over his own voltage; the power factor on the three-phase side can be adjusted at will ; and the maximum demand can be kept within bounds, notwithstanding the heavy currents that may be drawn from the singlephase generator at times of short-circuit. The main drawbacks to this plant are the high first cost and the poor efficiency. Owing to the low efficiency of the singlephase generator, especially when built with heavy armature conductors for large currents, the efficiency of the whole set is usually very poor. A 500 k.v.a. size has an efficiency of about 85 per cent.

\section{(4) Single-phase Current from Three-phase Supply WITH BALANCER.}

In order to secure a higher efficiency than can be obtained from a motor-generator, and a better specific use of the material employed, a number of different types of balancers have been proposed for balancing a three-phase system that would otherwise be thrown out of balance by a heavy single-phase load. These may consist either of stationary apparatus, such as choke coils or condensers, or of running machines, which may be either synchronous or asynchronous.

What is meant by "out of balance."-Before considering the various types of balancers, it is necessary to define more exactly what we mean by a three-phase system being out of balance. The generating plant in a three-phase power station might conceivably be so large and its impedance so low that quite a large single-phase load might be thrown on one phase, and yet the voltage might remain practically undisturbed; so that from the consumer's point of view the system might be considered in balance. It may even be that, through some slight dissymmetry in the winding of the generators, the voltages at no load are slightly unsymmetrical; and that when the single-phase load is thrown on, the balance of the voltages becomes perfect. We see that it is necessary to distinguish between unbalanced currents and unbalanced voltages; and in considering voltages and currents their phases and wave-forms are important as well as their virtua! values.

Let us take first a three-phase system in which the voltages and currents are of pure sine wave-form. Let the voltages measured from the star point to the terminals be :

$$
\begin{aligned}
& e_{a}=\mathrm{E}_{a} \cos \left(\omega t-a_{a}\right), \\
& e_{b}=\mathrm{E}_{b} \cos \left(\omega t-2 \pi / 3-a_{b}\right), \\
& e_{i}=\mathrm{E}_{i} \cos \left(\omega t-4 \pi / 3-a_{c}\right) .
\end{aligned}
$$

Let the currents in the three legs be:

$$
\begin{aligned}
& i_{a}=\mathrm{I}_{a} \cos \left(\omega t-\phi_{a}\right), \\
& i_{b}=\mathrm{I}_{b} \cos \left(\omega t-2 \pi / 3-\phi_{b}\right), \\
& i_{c}=\mathrm{I}_{c} \cos \left(\omega t-4 \pi / 3-\phi_{c}\right) .
\end{aligned}
$$


Then the voltages are in. balance when

and

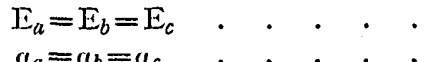

In a mesh-connected system the angles between the voltage vectors are dependent upon the values of the voltages, because the vector sum of the voltages must be zero. In this case (I) and (2) are not independent. We may, however, consider the star-connected case where the phase angles.are independent of the voltages.

The currents are in balance when

$$
\begin{array}{lllll}
\mathrm{I}_{a}=\mathrm{I}_{b}=\mathrm{I}_{c} \\
\phi_{a}=\phi_{b}=\phi_{c}
\end{array} \quad \cdot \quad \cdot \quad \cdot \quad \cdot \quad \cdot \quad \cdot \quad \cdot
$$

In a three-phase star-connected system not provided with a fourth wire, the phase angles of the currents are dependent upon the values of the currents, because the vector sum of the currents must be zero. Therefore conditions (3) and (4) are not independent. We may, however, consider the perfectly general case where a fourth wire is provided and where the currents and angles are independent.

If a symmetrical generating system has impedances of finite value, any departure from the conditions of balance in the currents causes a want of balance in the voltages. On the other hand, if the impedances in the generator and line are unsymmetrical, the voltage at the consumer's terminals will be unbalanced even when he draws currents that comply with conditions (3) and (4) above. If the voltages at the terminals of consumer $\mathrm{S}$ are unbalanced (owing, let us say, to an unsymmetrical load drawn by consumer U), a load of symmetrical polyphase machinery having small impedance, when put in circuit by consumer $S$, will have the effect of bringing the voltages more nearly into balance. This is due to the fact that the line supplies unbalanced currents to S's symmetrical apparatus, so that even if the effect were almost to balance the voltages, $S$ can justly complain that his load is unbalanced. He would, in fact, have unequal heating in his windings owing to the unsymmetrical loading of U's apparatus. Meanwhile, the central station engineer might be congratulating himself on the fact that his voltages and currents were very nearly balanced. If, therefore, we wish to make a complete statement of the want of balance on any system, we must be precise as to the part of the system under consideration, stating whether the voltages are unbalanced as to amplitude or phase, and whether the currents are unbalanced as to amplitude or phase. This is all on the assumption that the voltages and currents are of pure sine wave-form; if not, there are of course very many more ways in which the system and parts of the system may be unbalanced.

Returning to the case of pure sine wave-forms, there is another way of considering the unbalanced load. In a single-phase circuit in which the voltage is $e=\mathrm{E} \sin \omega t$ and the current is $i=\mathrm{I} \sin .(\omega t-\phi)$ the expression for the power is

$$
p=\frac{1}{2} E I \cos \phi-\frac{1}{2} E I(\cos 2 \omega t-\phi)
$$

The first term represents a constant flow of power. The second term represents a double-frequency alternating flow.

In a three-phase system we have in general, in addition to the constant flow terms, the three alternating terms:

in $\operatorname{leg} \mathrm{A}$,

in leg $B$,

in leg $\mathrm{C}$,

$$
\begin{aligned}
& \frac{1}{2} \mathrm{E}_{a} \mathrm{I}_{a} \cos \left(2 \omega t-\phi_{a}\right), \\
& \frac{1}{2} \mathrm{E}_{b} \mathrm{I}_{b} \cos \left(2 \omega t-4 \pi / 3-\phi_{b}\right), \\
& \frac{1}{2} \mathrm{E}_{c} \mathrm{I}_{c} \cos \left(2 \omega t-8, \pi / 3-\phi_{c}\right) .
\end{aligned}
$$

If now the phases are balanced so that $E_{a}=E_{b}=E_{c}$, $\mathrm{I}_{a}=\mathrm{I}_{b}=\mathrm{I}_{c}$, and $\phi_{a}=\phi_{b}=\phi_{c}$, these alternating terms can be represented by three equal vectors spaced at $120^{\circ}$ to one another, which rotate at twice the frequency of the supply (see Fig. I). As the sum of equal vectors

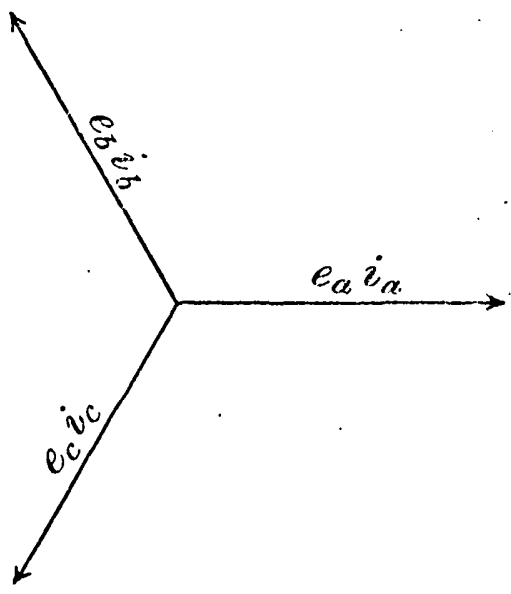

Fig. I.

so placed is equal to zero, the alternating components of the power balance one another when taken for the system as a whole. Thus we get, as Steinmetz has pointed out,* another test of the balance of the

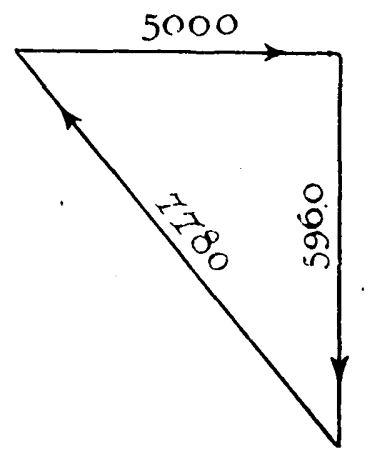

FIG. 2.

loads. If the sum of the three alternating components of the power is zero, the load is balanced in the sense that the single-phase load is on the whole eliminated and the power flows from the generator in an even stream ; but if the sum is not zero there is a fluctuating flow of power from the generator.

$$
\text { " "The Theory and Calculation of Electric Circuits." p. } 314 .
$$


Elimination of single-phase power components without "balance of phases."-If the conditions (I), (2), (3), and (4) above do not apply, then the alternating components of the power may or may not balance out one another. It may happen by chance or design that the amplitude and phase of three alternating power components are such that the three vectors representing them would form the sides of a triangle, as in Fig. 2, with the arrow-heads (showing the sense of the vectors) following one another consecutively. In this case the alternating components of the power balance one another, although it may be that neither the currents nor the voltages are balanced.

In Appendix II there is worked out an example in which the power is balanced according to Steinmetz's definition of balance, although the currents and voltages are not balanced.

Balancers. Stationary apparatus.-Where a polyphase load has been unbalanced by the addition of a single-phase load, it may be balanced by the addition of a wattless load taken by a choke coil or a condenser. Steinmetz has shown * that where a load is unbalanced and the resultant of the alternating components of the power is equal to $\frac{1}{2} \mathrm{EI} \cos (2 \omega t-\phi)$ it is possible to balance the system (according to his definition of balance) by the addition of a choke coil (of no resistance) fed with a voltage $\mathrm{E}^{\prime} \sin (\omega t-\beta)$, where $\beta=\frac{1}{2} \phi+\frac{1}{2} \pi$ and taking a current $\mathrm{I}^{\prime} \sin \left(\omega t-\beta-\frac{1}{2} \pi\right)$, where $E^{\prime} I^{\prime}=E I$. Or the system may be balanced by the addition of a capacity fed from the voltage $E^{\prime} \sin (\omega t-\beta)$, where $\beta=\frac{1}{2} \phi-\frac{1}{4} \pi$.

If we apply this method to the balancing of a threephase circuit which is carrying a single-phase load, it will be found that for some loads the addition of the choke coil gives a true balance, according to the definition on page III; but that for other loads the balance (while it is such as to bring to zero the resultant alternating components of power) is not such as to comply with conditions (I), (2), (3), and (4) of page III.

In Appendix III is given a graphic construction, which shows how it is that the addition of a choke coil in the example given by Steinmetz brings about a balance of phases. If, however, we apply Steinmetz's method to the case of a single-phase furnace fed from a three-phase supply, when the furnace is taking a current lagging $45^{\circ}=\phi$, we find that we do not necessarily get symmetrical currents. Whether we do or not, depends upon the particular voltage components from the three phases that we take to build up the voltage $E^{\prime} \sin (\omega t-\beta)$.

In Appendix IV is shown a case where the addition of a choke coil fed from the voltage $\mathrm{E}^{\prime} \sin \left(\omega t-\beta^{\prime}\right)$, and taking such a current as to bring the sum of the alternating components of power to zero, nevertheless fails to bring about balance of phases as defined on page III.

It is, however, possible, by taking three transformers of suitable ratios, to build up the voltage $e^{\prime}$ from components of $e_{a}, e_{b}$, and $e_{c}$ such that the final currents in all phases are exactly balanced when the choke coil is in circuit with $e^{\prime}$. The components of the voltages to be taken in order to meet this condition are seen from Fig. 37 in Appendix V.

- "The Theory and Calculation of Electric Circuits," p. $3^{18 .}$
It will be seen that the addition to the system of the choking coil in question, while it brings about a balance, increases the wattless load on the system. Now that condensers of large capacity. can be manufactured at fairly reasonable prices, it would be possible to use a condenser instead of a choke coil, with the effect of improving the power factor at the same time as balancing its load. In Appendix VI is given the construction which shows how it is possible to balance the currents as well as to reduce the alternating components of the power to zero in the condenser case (see Figs. 39 and 40). Such an arrangement, however, has the drawback (apart from its first cost) of requiring to be switched in and out with the furnace load. If it is left always in circuit it will produce as much outof-balance when the furnace is not taking current as the furnace produces when no compensator is employed. It would, of course, be possible to make automatic gear for switching in more or less capacity as the load on the furnace changed; but such automatic switching arrangements are not looked upon with favour by electrical manufacturers.

Balancers. Running machines.-A running machine such as a synchronous motor or asynchronous motor is able to take energy from the circuit at one part of a cycle, store it as kinetic energy, and return it to the circuit at another part of the cycle. In this way it is able to neutralize the alternating component of the power mentioned on page III. Any symmetrical threephase motor or generator running on the system and having an armature of low impedance will help to balance the voltages on a system when the voltages are unbalanced. Such a machine balances the voltages by taking unbalanced currents from the line. These unbalanced currents, multiplied by the impedances of their respective armature circuits, give the unequal voltage-drops that represent the differences, between the unsymmetrical voltages $e_{a}, e_{b}$, and $e_{c}{ }^{*}$ of the line, and the symmetrical back voltages $e_{a}^{\prime}, e_{b}^{\prime}$, and $e_{c}^{\prime}$ of the motor or generator. If the impedance of the armature is exceedingly low, these differences will be exceedingly small-that is to say, the system will be very nearly balanced.

If the armature impedance is not negligibly small, it is possible to obtain balance by connecting some kind of boosting appliance in series with the balancer to compensate for the impedance drop in the armature. In this way a comparatively small balancer can be compelled to take an unsymmetrical load sufficient to balance perfectly the voltage of the system. The main distinction between different kinds of balancers lies in the kind of boosting appliance employed. The methods of boosting may be roughly classified as follows :

(a) Unsymmetrical numbers of turns in the balancer winding.

(b) Booster transformer in series with the winding.

(c) Addition of choke coils or condensers to some of the phases.

(d) Booster generator in series with the winding:

(e) The generation of an oppositely-rotating magnetic field of double the frequency. 
With any of these methods, the balancer may be either synchronous or asynchronous. A synchronous balancer can be used to correct the power factor of the system, whereas an asynchronous machine usually. throws a lagging wattless load on the system.

(a) Unsymmetrical numbers of turns on balancer winding. - The first method is illustrated in Fig. 3,* which shows a single-phase load D supplied from a

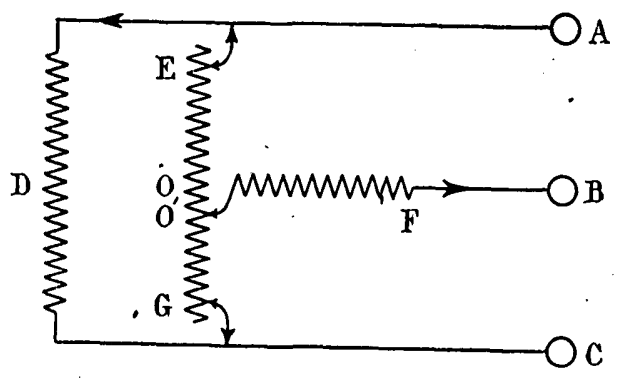

FIG. 3.

three-phase supply, the terminals of which are A, B and $C$. A balancer (which may be either synchronous - or asynchronous) is shown with its windings $E, F, G$ connected so as to balance the load. The windings $E$ and $G$ together may form one of the phases of a two-phase generator, $F$ forming the other phase. In this case the number of turns in $F$ is arranged so as to give a symmetrical three-phase voltage at the ter-

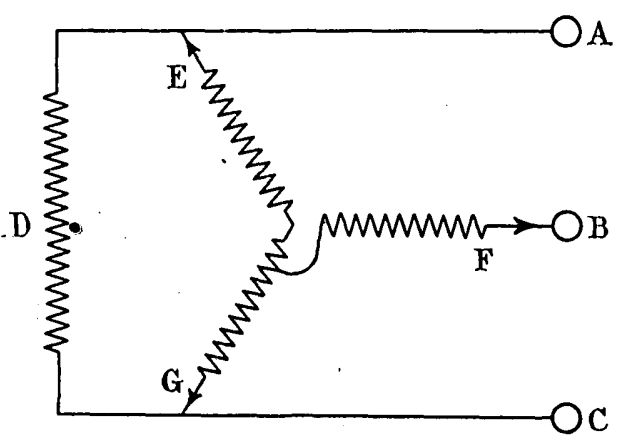

FrG. 3A.

minals. Or, if preferred, the winding $E, F$, and $G$ may be wound as an ordinary three-phase generator (Fig. 3A). In either case tappings are brought out from $E \mathrm{G}$ near the star point so that the inner end of . F may be connected in an unsymmetrical manner. Tappings may also be brought out near the outer ends . of $\mathrm{E}$ and $\mathrm{G}$.

Let us first connect $F$ to the centre point of $\mathrm{EG}$ and see what will happen when a single-phase load : is thrown on $\mathrm{D}$. "To fix our ideas we shall consider the case of a synchronous balancer with the excitation

* All the cluck diagrams in this paper are supposed to rotate anti-clockwise. It will be seen on inspection of the diagrams relating to the various balancers that in some cases the back E.M.F. of phase $A$ is shown ahead of the line impressed E.M.F. in A and sometimes behind the impressed E.M.F. This is as "it should be. In Fig. 4, for instance, it is ahead because the field magnet is pushed ahead by the phase $\mathrm{B}$ acting as a motor. In Fig. 6 it is behind inotwithstanding the position of the field magnet, which being behind the inotwithstanding the position of the field magnet, which being behind the in combination with the booster E.M.F., gives the desired load on the balancer. arranged to give unity power factor. If the generators and mains supplying $A, B$, and $C$ had an infinitely small impedance, then, whatever single-phase load we might draw, the three-phase voltage would remain balanced, and the balancer would run light, taking only a small synchronizing current. In practice, the generators have a certain impedance; which (as shown on page 127)

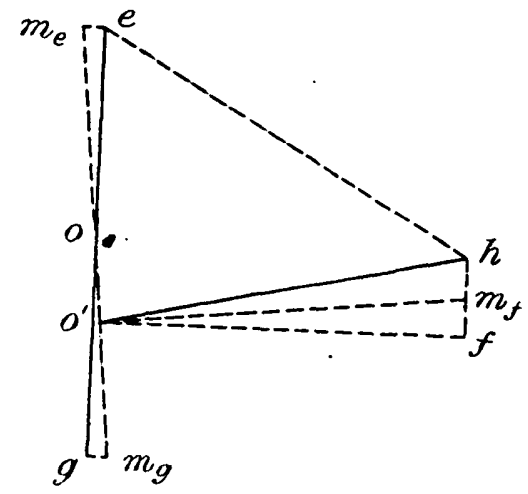

FIG. 4 .

caluses the voltage $\mathrm{A} C$ to fall. The winding $\mathrm{E} \mathrm{G}$ will then have a small tendency to supply current to $D$, and the winding $F$ will operate as a. motor winding. The synchronous impedance of the balancer will, however, limit the load supplied to $D$, and it will only be in so far as the voltage on the system is thrown out of balance that any load can be obtained from EG. If now we displace the inner end of $F$ in the manner shown in Fig. 3A, we can obtain a large balancing load from $\mathrm{E} \mathrm{G}$ while the three-phase voltage remains

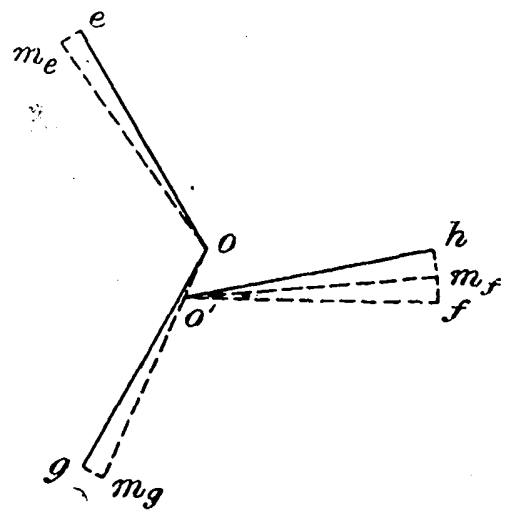

Frg. 4.A.

balanced. The vector diagram is shown in Fig. 4 For the purpose of this figure, the arrow-heads in Fig. 3 show the directions of currents and E.M.F.'s taken as positive. Moreover, it should be remarked that the phase of the voltage at the terminals of $E \mathrm{G}$ is taken as the standard of phase ; that is to say, that a vertical line is arbitrarily taken to represent the phase of this terminal voltage, and the phase positions of all other vectors are set off from this vertical line, according to 
the phase difference between their respective quantities and this terminal voltage. If $o e$ and $o g$ represent the terminal voltages of $\mathrm{OE}$ and $\mathrm{O} G$ respectively when the balancer is on load, it is clear that the generated voltages in these windings must be slightly ahead in phase if $O E$ and $O G$ are to supply currents as generators. The phase position of the field magnet being ahead of the terminal voltage the generated voltages may be represented by $0 m_{c}$ and $o m_{g}$ respectively. The field magnet, as will be seen directly, is forced ahead by the $F$ winding and gives rise to this lead in the phase of $o m_{c}$ and $o m_{g}$. If the load current is nearly in phase with the E.M.F., the impedance drop in $\mathrm{OE}$ and $\mathrm{OG}$ may be represented by $m_{e} e$ and $m_{g} g$. The vector $o^{\prime} m_{f}$, which is at right angles to $m_{b} m_{g}$, gives the generated voltage in $F$. Now the winding $F$ is carrying a motor load, so that the impedance drop must be set off in a counter-clockwise direction $m_{f} h$. Let the inner end of $\mathrm{F}$ be displaced from the star point $\mathrm{O}$ to the point $O^{\prime}$ (Fig. 3), and let the voltage in $O O^{\prime}$ be $O O^{\prime}$ (Fig. 4). At no load the voltage generated in $F$ will be $o^{\prime} f$. At full load, the generated voltage will be $o^{\prime} m_{f}$, owing to the displacement of the field magnet, and the terminal voltage will be $o^{\prime} h$. If now the displacement from $o$ to $o^{\prime}$ downwards is approximately equal to the displacement between $h$ and $f$, the points $e, h$, and $g$ will fall near the corners of an equilateral triangle; that is to say, the voltages are nearly balanced. In practice the displacement of the inner end of $F$ does not exactly compensate for the displacement of $h$ to $f$, owing to slight phase displacements caused by the resistances of the circuits. Balance can be more accurately obtained by using the taps at $\mathrm{E}$ and $\mathrm{G}$. The drawback to the use of these unsymmetrical connections is that at no load they cause as much outof-balance as they cure when the load is on. Proposals * have been made for altering the taps on the windings automatically as the load comes on, but this involves rather undesirable complications.

(b) Boosting transformers in series balth bancer windings.-It is clear that it is possible to compensate for the inductive drop in the balancer windings by injecting electromotive forces of the right amount and phase, by means of transformers, in series with the balancer windings. In I9I5 a single-phase furnace project was brought before the British Westinghouse Company, and experiments were made to see how far a synchronous motor could be made to operate as a balancer by means of injected E.M.F.'s. The apparatus was just such as could be found on the test bed at the time, and consisted of a $250-\mathrm{kw}$. rotary converter acting as a balancer fed from a $300-\mathrm{kw}$. three-phase star-connected alternating-current generator. The single-phase load consisted of an iron wire rack and a choke coil, and had a power factor of about 0.8 . The boosting transformers were the ordinary workshop testing-transformers provided with a large number of taps on the secondary, and were not very suitable for the work. The connections to the terminals of the three-phase generator are shown in Fig. 5. It was found that the rotary converter could be made * U.S. patent specifications Nos. 114,167 and 136,016 of 1916 . to balance the currents fairly well. With a singlephase load of 165 k.v.a. on the rack, the currents from the terminals of the alternating-current generator were balanced to within 6 per cent of the mean current. This was good enough for practical purposes, and if it had been possible to get better control of the boosting: voltage a better balance could have been obtained. The rotary converter, in addition to balancing theload, provided all the wattless current for the singlephase load, the current from the alternating-current: generator being drawn'at unity power factor. Owing: to the unisteady conditions prevailing at the time, it. was not possible to find the exact angles between the various voltages and currents; but there was no very. marked departure from the ideal case represented in Fig. 6. Here the vertical line $O V_{a}$ is taken as thestandard of phase, and represents the pressure at the terminal A measured from the star point of the generator. The vectors $V_{P}, V_{Q}$, and $V_{R}$ are the line pressures $C$ to $A, A$ to $B$, and $B$ to $C$ respectively. The directions:

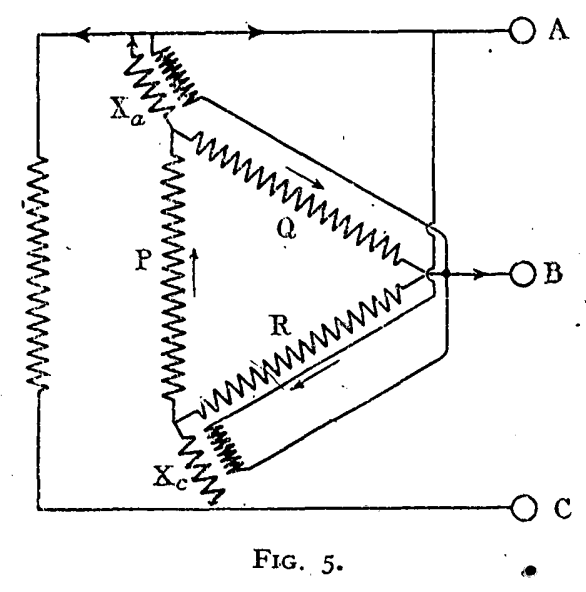

that are taken as positive in each wire for the purpose of the clock diagram are shown by the arrow-heads. in Fig. 5. The boosting. and synchronizing E.M.F.'s. are too small to be shown satisfactorily in Fig. 6, and are therefore shown to a different scale in Fig. 7 . Neglecting these for the moment and returning to. Fig. 6, we may consider the generator and motor functions of the balancer separately, and afterwards. combine the generator and motor currents to obtain the actual current at each terminal.

We have in the first place a current of 530 amperes. supplied to the single-phase load $D$; this is shown by the vector $O I_{D}$ lagging $36^{\circ}$ behind the voltage $V_{p}$. Then we have the three motor currents $\mathrm{I}_{a}, \mathrm{I}_{b}$, and $\mathrm{I}_{c}$ flowing. from the three-phase generator into the balancer, each in direct opposition of phase to the star backE.M.F.'s of the balancer. As the efficiency of the balancer in this experiment was very low, these motorcurrents were about 300 amperes, giving an input of $3 \times 300 \times 180=162 \mathrm{kw}$. for a single-phase output of $530 \times 310 \times 0.8=132 \mathrm{kw}$. In combining the generator and motor currents we must of cousse have regard to the arrow-heads in Fig. 5. According to the conventions chosen, $I_{D}$ is a positive current when flowing: 
in $\mathrm{D}$ in the direction of the $\mathrm{D}$ arrow-head; and as the arrow-head at $X_{a}$ runs concurrently with it, $I_{D}$ and $I_{a}$ must be added, as shown in Fig. 6 , to get the actual current $I_{A}$. The arrow-head at $D$ is, however, opposed to the $\mathrm{C}$ arrow-head, and so to get the current at $C$ we must subtract $I_{D}$ from $I_{C}$. This gives us $O I_{C}$. shown by the chain-dotted line. The current at $B$

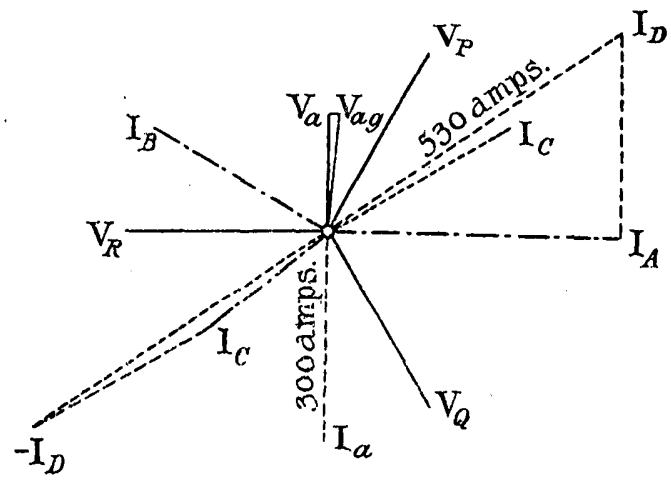

FIG. 6.

is of course $I_{B}$. Thus we get the currents $I_{A}, I_{B}$, and $I_{C}$ that would flow in a star-connected balancer. The fact that the rotary converter is mesh-connected does not affect the deductions made below. The inductive drop in the armature of the converter was about 3.8 volts for each roo amperes drawn from a slip-ring; and the resistance drop was 0.35 volt for each 100

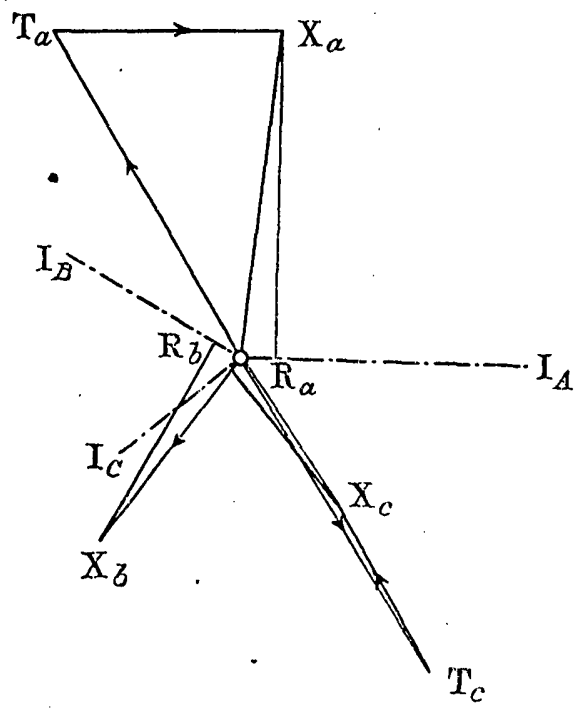

FIG. 7 .

amperes. Referring now to Fig. 7 , we set off the resistance drop $O \mathrm{R}_{a}$ along the vector $\mathrm{I}_{a}$, and the reactive drop $\mathrm{R}_{a} \mathrm{X}_{a}$ to get the impedance drop $O \mathrm{X}_{a}$ in phase $\mathrm{A}$. If this impedance drop is to cause no disturbance to the balance of the voltages, it must be supplied by the boosting transformer (shown at $\mathrm{X}_{a}$ in Fig. 5) acting in conjunction with the synchronizing voltage $\mathrm{V}_{a} \mathrm{~V}_{a g}$ (see page II6). The synchronizing voltage $\mathrm{T}_{a} \mathrm{X}_{a}$ (due to the displacement of the field magnet behind the terminal voltage) is transferred from Fig. 6 andi drawn to the large scale. of Fig. 7. We then find that if the boosting transformer supplies the voltage $\mathrm{OT}_{a}$, the two voltages $O T_{a}$ and $T_{a} X_{a}$ will supply the required impedance drop. In the same way we can find the boosting voltage $\mathrm{OT}_{c}$ required from transformer $\mathrm{X}_{c}$. It will be seen that for this particular single-phase load the boosting voltage is almost parallel to the voltage $\mathrm{V}_{Q}$ (Fig. 6). The primaries of the boosting: transformers were connected to the terminals $\mathrm{A}$ and $\mathrm{B}$, and the number of turns was adjusted so as to give the best possible balance. This arrangement, however, makes no provision for balancing the resistance drop. in phase $B$. The reactive drop in phase $B$ is almost balanced by the synchronizing voltage. This is because the displacement of the field magnet behind the terminal voltage becomes automatically greater and greater,

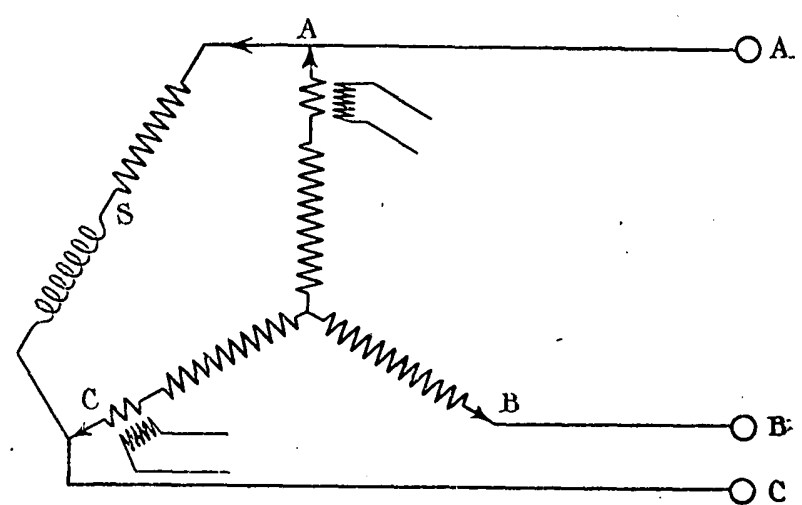

Fig. 8

until the synchronizing voltage is great enough to supply the requisite motor current, which in this casewas 300 amperes. It was found that if the singlephase load was thrown off with the boosting transformer still in action, the rotary converter took from the alternating-current generator an unbalanced load of a magnitude comparable with the single-phase load thrown off. In fact, for every change of the singlephase load it was necessary to alter the taps of the boosting transformer, and for different power factors of the single-phase load it was necessary to take different combinations of phases in order to supply a boosting. voltage in the right phase.

A project for a balancer for a 2,400-k.v.a., 0.7 power factor, single-phase furnace was considered in some detail, in order to arrive at the approximate cost and efficiency of such a balancer, and to ascertain the amount and phase of the boosting voltages. The balancer proposed in this case was to be of the synchronous type, built exactly like a synchronous motor, with a heavy amortisseur and with a rather large section of copper in one of the phases of the armature. It was intended that the balancer should carry an excitation sufficient to raise to unity the power factor of the load on the three-phase system. The circuit diagram, with the directions taken as positive in each wire, is shown in Fig. 8. Fig. 9 gives the clock 
diagram for the balancer when balancing a singlephase load of $2,400 \mathrm{k}$.v.a. at 0.7 power factor. The pressure of the three-phase mains is 6,600 volts. The figure is drawn to the scale of one millimetre $=200$ volts ; one millimetre $=$ I0 amperes. The single-phase current Is amounts to 364 amperes, lagging $45^{\circ}$ behind the voltage $\mathrm{V}_{a c}$. The currents $\mathrm{I}_{a}, \mathrm{I}_{b}, \mathrm{I}_{c}$ are the balanced three-phase currents taken from the supply mains,

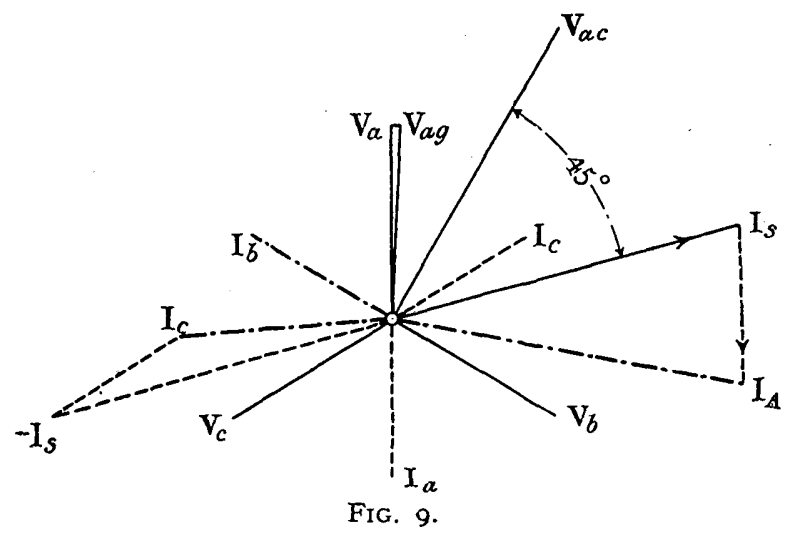

opposite in phase to the no-load back-E.M.F.'s $V_{a}$ $\mathrm{V}_{b}$, and $\mathrm{V}_{c}$ generated in the balancer. The sum of $I_{S}$ and $I_{a}$ gives the vector $I_{A}$, the actual current in phase $A$ of the balancer. The difference between $I_{c}$ and $I_{S}$ gives $I_{C}$, the actual current in phase $C$ of the balancer. The current $I_{b}$ is of course the actual current in phase B. This disposition of currents is brought about partly by the boosting E.M.F.'s and partly by

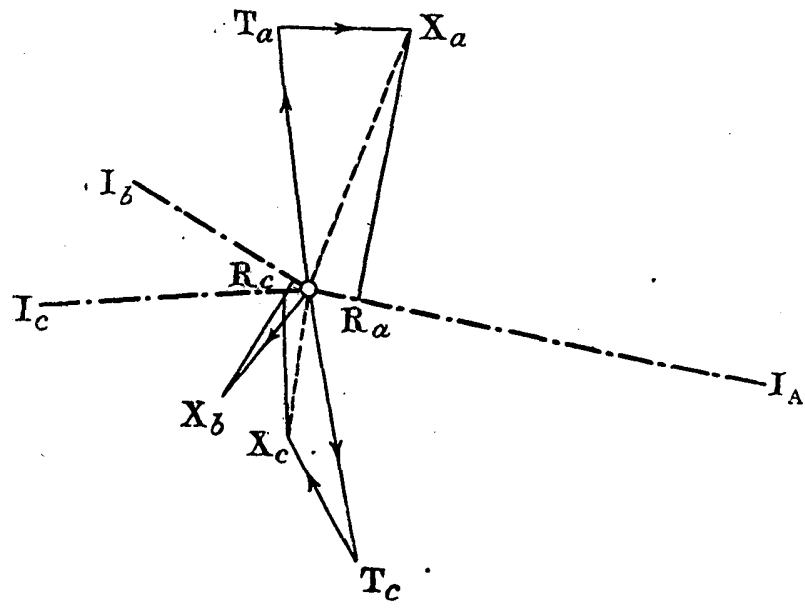

FIG. Io.

the synchronizing E.M.F.'s operating between the motor and the generator. The synchronizing E.M.F. in phase $A$ is shown by the short vector $V_{a} V_{a g}$ approximately at right angles to $O V_{a}$. $O V_{a g}$ gives the phase position of the generated voltage in the balancer on full load. It should be noted that as the balancer is running as a motor the phase position is as shown, even on the phases of the balancer that are to operate as generators. It is by virtue of the boosting E.M.F. shown in Fig. xo that phases $\mathrm{A}$ and $\mathrm{C}$ are able to operate as generators. The reactance drop in one phase. of the armature of the balancer is calculated to be about II. 5 per cent of the 3,800 volts generated in that phase, for a current of 364 amperes. The resistance drop, including eddy-current losses, will amount to about 2 per cent. In order to arrive at the amount and phase positions of the required boosting voltages, we must refer to Fig. ro, which is drawn to a larger scale ; namely, one millimetre $=\mathrm{I}_{5}$ volts ; 2 millimetres $=\mathrm{I}_{5}$ amperes. The currents $I_{A}, I_{C}$, and $I_{b}$ are transferred from Fig. 9. We mark off $O R_{a}$ to give the resistance drop in phase $A$, and $R_{a} X_{a}$, at right angles, to give the reactive drop in phase $A$; so that $\mathrm{X}_{a} \mathrm{O}$ gives the impedance drop. To overcome this, it is necessary to have a boosting E.M.F. O T $T_{a}$, which when added to the synchronizing E.M.F. $\mathrm{T}_{a} \mathrm{X}_{a}$ gives a voltage of right a mount and phase to overcome the impedance drop $\mathrm{X}_{a} \mathrm{O}$. Similarly in phase $\mathrm{C}$ the boosting voltage $\mathrm{OT}_{c}$ must be injected in order that, combined with the synchronizing voltage $\mathrm{E}_{c} \mathrm{X}_{c}$, it may overcome the reactive drop $\mathrm{X}_{c} \mathrm{O}$. The synchronizing voltage $\mathrm{O} \mathrm{X}_{b}$ is sufficient to drive the current $\mathrm{OI}_{b}$ through the reactance of phase $B$. From this it is seen that the requisite boost in phases $A$ and $C$ amounts to about 400 volts, and its phase is $10^{\circ}$ in advance of the E.M.F. $V_{a}$. It might be supplied by a transformer connected between terminal $A$ and a tapping on winding $B$ near the starpoint.

The calculated efficiency of a balancer of this size was 93 per cent, as against an efficiency of 87 per cent for a motor-generator. The estimated cost (war-time prices) was $6_{5}$ per cent of the cost of a motor-generator to do the same work. As it would be necessary to supply, in addition to the balancer, a transformer to reduce the pressure from 6,600 to 220 volts, the cost of the balancer with exciter and starter, step-down transformer and boosting transformer, would not differ very much from the cost of the motor-generator, and the combination would have an efficiency only 3 or 4 per cent higher than that of a motor-generator.

It was thought by the author that it should be possible to combine in one machine the balancing and powerfactor-correcting functions of the synchronous motor with the functions of a step-down transformer and boosting transformer. This combination has been made in the balancer described later in the paper.

The drawback to the connection of boosting transformers permanently in series with various phases is, that when the single-phase load is taken off the system the amount of out-of-balance current taken by the various phases is the same as the out-of-balance current that there would be on full load if no boosting transformers had been used. This could be avoided by having adjustable taps on the transformer that could be controlled by hand or, automatically as the load came on and off.*

(c) Addition of choke coils or condensers to some of the phases.-It will be seen in the methods described under the last heading $(b)$ that while we have voltages that are balanced when measured outside the boosting transformers (say at the terminals $A, B$, and $C$ in Fig. 8), the voltages measured at the terminals of the * U.S.A. patent specifications Nos. 114, IG 7 land $13,36,016$ of 1916 
balancer itself are not balanced. A want of symmetry here is necessary in order to make the balancer take its load. There are numerous ways in which this want of symmetry can be produced at the terminals of the balancer by the addition of choke coils or condensers in some of the phases, while at the same time the symmetry of the voltages is preserved at the mains. A typical method due to Lawrence * will serve to illustrate the principle of all these methods. It has been proposed for balancing the voltage at the terminals of a three-phase motor on a locomotive fed from a single-phase trolley line. Here single-phase power from transformer $T$, Fig. II, is being converted into three-phase power. A rotating balancer A B C (which may be either synchronous or asynchronous) is used to equalize the flow of power. A special choke coil $\mathrm{X} \mathrm{Y}$ with two windings is placed in series with lines $\mathrm{L}_{a}$ and $\mathrm{L}_{c}$ leading direct from the terminals of the secondary of the transformer. The line $\mathrm{L}_{b}$ is fed from a mid-point of the secondary and passes through one of the phases of a two-phase balancer on its way to the motor. The arrow-heads on the circuit diagram denote the directions on each wire taken as positive for the purpose of the clock diagram. The trans-

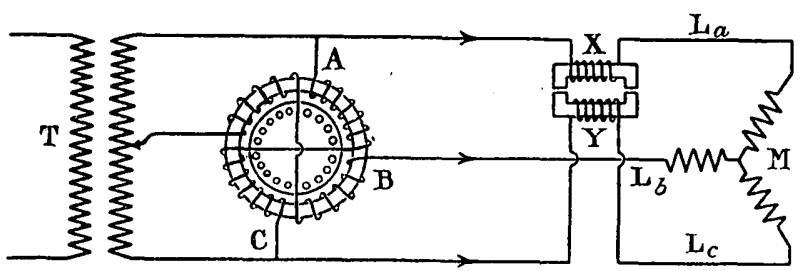

FIG. II.

former $\mathrm{T}$ may be taken to be supplying power to the three-phase motor $\mathrm{M}$ or to any other three-phase apparatus. The distribution of voltage in the threephase circuit will depend upon the kind of machines connected. We can distinguish broadly three cases :-

(a) Where the load on the three-phase circuit consists of balanced machines (such as synchronous motors) having infinitely small impedance.

$(\beta)$ Where it consists of dead resistance.

$(\gamma)$ Where it consists of machines having finite impedance.

In case $\left(a^{\prime}\right)$ no balancer is needed, and full load can be supplied from $T$ without upsetting the balance of the voltages. In case $(\beta)$, if there were no balancer, no current would flow in the line $L_{B}$ and we should have a simple single-phase load across $L_{A} L_{C}$. If now a balancer be added and the non-inductive load made very small, we get the voltage distribution shown in Fig. I2. If the balancer is a synchronous one, it takes a small synchronizing current in phases $o a$ and $o c$ (which constitute one phase; but as $o$ is taken as the star point we must strictly regard them as two phases at $\left.180^{\circ}\right)$. It should be pointed out that in what follows the phase of $o a$ is taken as the standard of phase to which all other phases are referred; that is, the vector - U.S.A patent specification No. 110,815 of 1916 . representing the voltage at the terminals of the transformer secondary is taken as vertical. At no load, the phase position of the field magnet will be the same as $o a$. The phase position of the field magnet is the position from which the generated voltage in $B$ is determined. This generated voltage is at right angles to the generated voltage in $\mathrm{A}$.

If now the load is increased, $B$ will begin by taking its share of the load, and in acting as a generator will pull over the field magnet to, say, a position such as $o m_{a}$ in Fig. 13. Phases $\mathrm{A}$ and $\mathrm{C}$ will now be acting as motors. The phase of the generated voltage in $B$ takes up a position such as $m_{b}$. As there is a motor

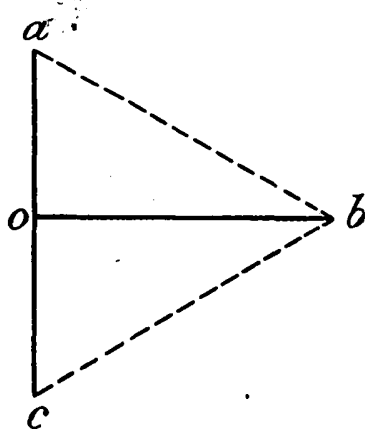

FIG. 12.

load on windings $\mathrm{A}$ and $\mathrm{C}$, the armature reaction $m_{a} a$ added to $o m_{a}$ gives the terminal voltage of $\mathrm{A}$ at $o a$, as before. The armature reaction in $\mathrm{B}$ is $m_{b} b^{\prime}$, so that the terminal voltage of $B$ is $o b^{\prime}$. This displacement of the vector $o b^{\prime}$ in the case of a resist. ance load does not have much effect upon the load taken by each phase, because that is chiefly controlled by the resistance in circuit; but if the resistance is replaced by a runing machine having a small impedance.

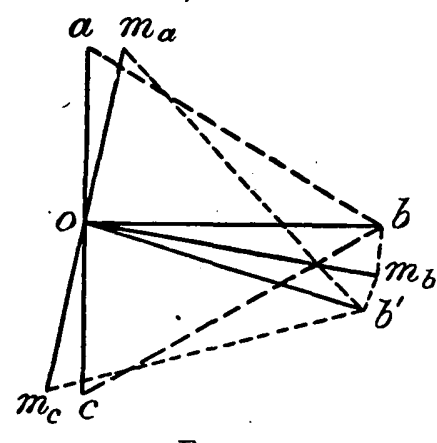

FIG. 13.

in its windings the displacement of $o b^{\prime}$ tends to take the generator load off the phase $B$, so that in the ordinary way, if nothing more is added to the apparatus; the balancer will not take much load until the phases of the receiving machine are distorted by a single-phase load by an amount corresponding to $b b^{\prime}$.

Now consider the effect of putting a choke $X Y$ in series with $\mathrm{L}_{a}$ and $\mathrm{L}_{c}$, as shown in Fig. Ir. Let the load consist of a symmetrical three-phase resistance. So long as the voltage phases are balanced, this three- 
phase resistance will take equal currents at $120^{\circ}$ apart from each of the lines. Let these currents be $I_{a}, I_{b}$ and $I_{c}$ shown in Fig. $I_{4}$ diawn from the true star point $\mathrm{O}^{\prime}$. The coils on $\mathrm{X} Y$ (for forward currents, according to the arrow-heads in Fig. II) are wound so as to give opposing magnetomotive forces on the choke coil. We must therefore reverse one of the vectors, say $I_{c}$, in getting the sum of the magnetizing effects of the two coils. This is shown in Fig. $\mathrm{I}_{4}$ by the vector $\mathrm{I}_{a}-\mathrm{I}_{c}$. The reactive voltage on the choke coil is nearly at right angles to this magnetomotive force, and is shown at $O^{\prime} x=a a^{\prime}=c^{\prime} c$. Adding $O^{\prime} x$ to $o a$ we get $o a^{\prime}$, and subtracting $O^{\prime} x$ from $o c$ we get $o c^{\prime}$. We now see that the voltages betwe the terminals of the resistance $a^{\prime} b^{\prime}, b^{\prime} c^{\prime}$, and $c^{\prime} \dot{w}^{\prime}$ are symmetrical. There are, of course, several minor difficulties. For instance, when the load is a running machine the phase of the load current may not be such as to give the required correction; but roughly the choke coil worlss in the right direction, and theoretically it should always be possible, by a suitable arrangement of choke coils

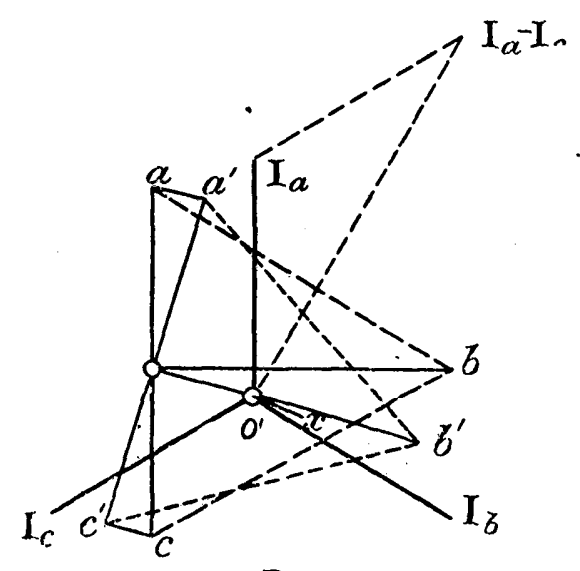

FIG. 14.

and condensers, to bring the added voltages $a a^{\prime}$ and $\& c^{\prime}$ into the right phase. The advantage of this method over the boosting-transformer method is that the injected voltage in the choke coil rises automatically with the load. Instead of electrostatic condensers it is of course possible to use electromagnetic machines such as synchronous motors and phase advancers.*

(d) Booster generator in series with the winding.It is clear that, instead of using boosting transformers in series with the various phases, it is possible to use a synchronous booster. In this way the phase and amount of the voltage injected into each leg can be controlled more easily than with transformers in series. Several methods have been proposed, based upon this principle. $\dagger$ The most widely known is that of Alexanderson, described in a paper read by Alexanderson and Hill before the American Institute of Electrical Engineers $\ddagger$ in October rgr6. While Alexanderson's booster may from one point of view be regarded simply as a booster injecting E.M.F.'s which compensate for

* U.S.A. patent speciâcations Nos, $112,220,123,03 x$, and 129,976 of 1916 .

+ U.S.A. patent No. I,093,594 (1912)

" "Single-phase Power Proluction," Transactions of the American Instilute of Elodirical Engineors, x916, vol. 35, p. I315. the impedance drop in the balancer windings, Alexanderson himself prefers to look upon the operation as the injection of oppositely-rotating polyphase components. These oppositely-rotating components we prefer to consider under another heading.

In Fig. I5 are shown the three phases, A, B, and C of the stator of the synchronous balancer connected to

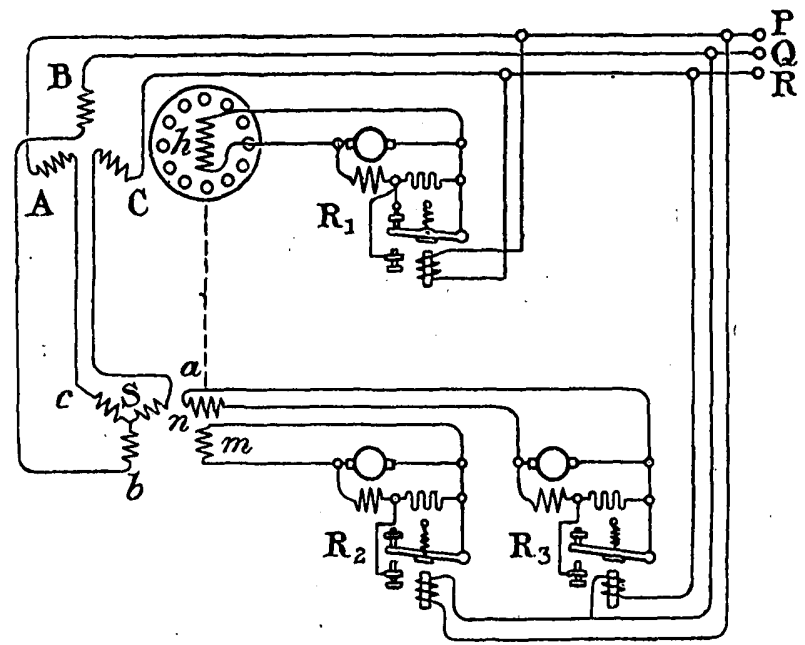

FiG. 1.5 .

a supply system $P Q R$, which is supposed to be thrown out of balance by having a single-phase load connected between $P$ and $R$ The function of the balancer is to correct the voltage by supplying current as a generator from phases $A$ and $C$ and taking current as a motor in phase $B$. These generator and motor currents are

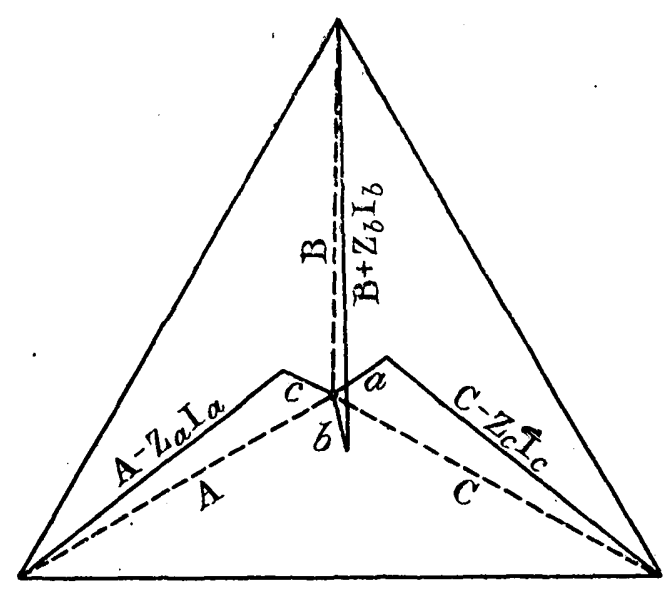

Fig. 16 .

controlled by means of a synchronous booster, the stator windings of which are shown at $a, b$, and $c$. The field magnets of the main machine and booster are rigidly connected on the same shaft and revolve in synchronism with the supply. The booster windings are connected between the inner ends of the balancer windings and the star point $S$. It will be seen that phases $A$ and $C$ of the balancer are connected to phases $c$ and $a$ respectively of the booster, while phase $b$ of the booster is 
connected to phase $\mathrm{B}$ of the balancer, so that its E.M.F. opposes the E.M.F. of the balancer. The field magnet of the balancer is excited by the winding $h$ fed from an exciter controlled by a Tirrill regulator $R_{r}$. The field magnet of the booster has two windings, $m$ and $n$, lake the windings of a two-phase rotor. The continuous current in these windings is controlled by the two Tirrill regulators $R_{2}$ and $R_{3}$ so that the orientation of the magnet field with respect to the iron core of the rotor can be shifted through an arc of 90 electrical degrees according to the behaviour of the regulators, which in their turn depend upon the distribution of voltage between $P, Q$, and $R$. It will be seen that the connections shown in Fig. I5 will (for a suitable orientation of the magnetic field of the booster) give a relation of the booster voltages to the balancer voltages such as that illustrated in Fig. I6.

In Fig. I 6 the short vectors representing the booster voltages are lettered $a, b$, and $c$. These are in series with the balancer voltages $\mathrm{C}, \mathrm{B}$, and $\mathrm{A}$ respectively, and have the effect of causing phases $A$ and $C$ of the

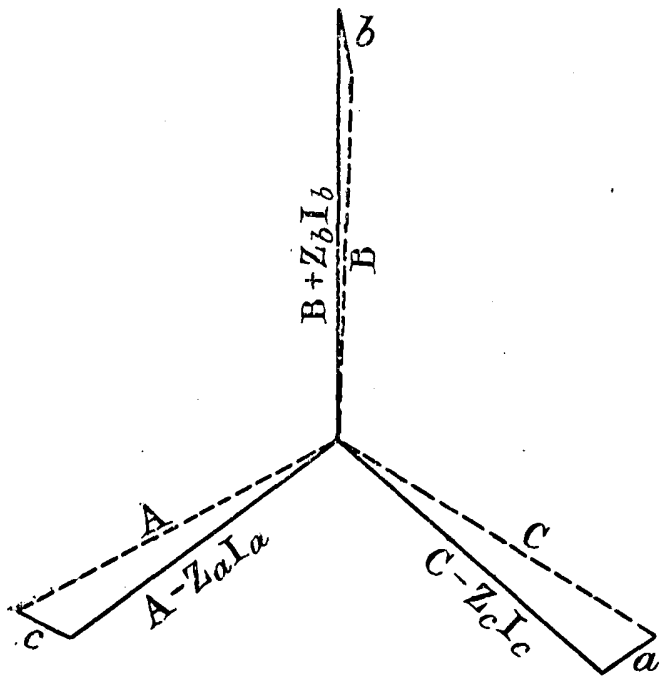

FIG. I7.

balancer to take a generator load, and phase B to take a motor load. When $\mathrm{A}$ and $\mathrm{C}$ are taking a generator Toad of low power factor, the terminal voltages would be disturbed in phase and reduced by the impedance drops $Z_{a} I_{a}$ and $Z_{c} I_{c}$ (see Fig. I6), but the phase and value of boosting voltages $c$ and $a$ are such as almost to restore the balance of the voltage at $\mathrm{P}$ and $\mathrm{R}$. When $\mathrm{B}$ is taking a motor load with a leading power factor, the terminal voltage would be increased to $\mathrm{B}+\mathrm{Z}_{b} \mathrm{I}_{b}$, but the booster voltage $b$ is subtracted from this and restores the balance between $P, Q$, and $R$. The vectors may either be laid out as in Fig. I6, in which they radiate from the star point just as the windings radiate in the diagram of connections, or they may be laid out as in Fig. 17 , in which form they are more comprehensible in comparison with Fig. 28. The advantage -f the booster-generator method of supplying the inductive drops in the balancer over the methods described under headings $(a),(b)$, and $(c)$ is, that in it the boosting voltages are most easily controlled in value and phase. However, since the boosting generator must have the same number of poles as the balancer, it cannot be built very cheaply, even though the output is small; and the cost of the exciters and regulating gear is by no means negligible.

(e) The generation of an oppositely-rolating magnetic field of double the frequency. - Several methods of balancing single-phase power by supplying currents of double trequency having the sense of rotation opposite to that in the main three-phase system have been described in patent specifications and published writings. As there is a great deal of confusion in writings upon this matter, it may be well, in the first place, to make a precise statement upon the point that is of chief importance in these cases, namely, the effect of an oppositelyrotating magnetic field in a running balancer. And in this connection we must consider the magnetic field produced by a polyphase armature when supplied with unbalanced currents.

Expression for the resultant magnctic field of a polyphase armature.-It is not possible to find an exact simple expression for the resultant field of a polyphase generator on load, because the disposition of the armature conductors in slots and the shapes of the iron parts of the poles lead to a complex field-form the shape of which changes as the field revolves. Any simple expression involving only the fundamental term of the Fourier series expressing the whole phenomenon must necessarily be of limited application ; but nevertheless it aids us in getting a conception of the main happenings in the machine. For this reason it has been customary for writers upon the subject to regard the armature magnetomotive force of a three-phase armature carrying a balanced load as giving rise to a sinusoidal field distribution superimposed upon the field produced by the exciting winding. Smith and Barling * have shown that the maximum ordinate of the fundamental wave of magnetomotive force under one pole, due to the armature ampere-turns, is equal to

$$
\frac{0.43 I_{a} Z_{a}}{\text { Number of poles' }}
$$

where $I_{a}$ is the virtual value of the armature current and $Z_{a}$ is the total number of conductors in the armature. The maximum value of the magnetomotive force in reality changes between the values

$$
\frac{0_{437 I_{a} Z_{a}}}{\text { Number of poles }} \text { and } \frac{0.407 \mathrm{I}_{a} Z_{a}}{\text { Number of poles }}
$$

This variation gives rise to a triple-frequency alternating effect, which may be regarded as being produced by six stationary single-phase poles per main pole-pair situated at the points where the windings of the various phases lie adjacent to one another. In what follows we shall neglect this triple-frequency alternating effect and confine our attention to the fundamental wave of magnetomotive force.

To fix our ideas, let us consider a two-pole armature having an ordinary full-pitch three-phase winding lying in three phase-bands $A, B$, and $C$ per pole. If

$$
\text { * Electrician, 1914, vol. 74, p. } 42 \text {. }
$$


the three-phase load is balanced, we may take the armature reaction as giving rise to this fundamental uniformly-rotating field. If the only load is a singlephase load thrown on to terminals $A$ and $C$, it will give rise to a single-phase magnetomotive force along

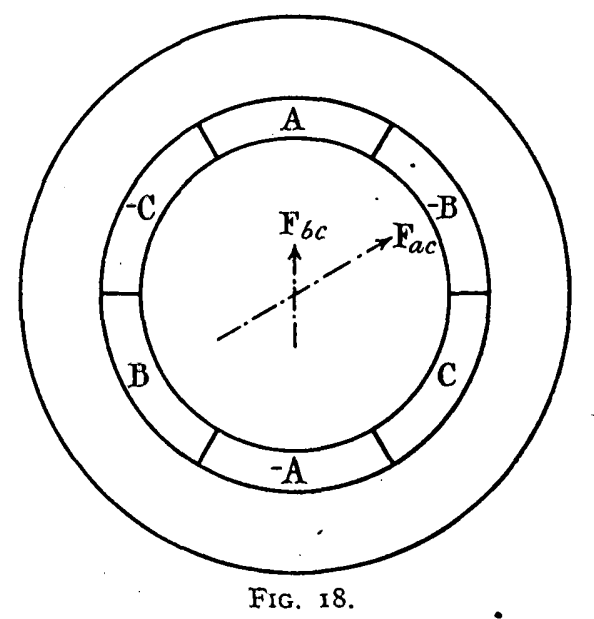

a path the centre line of which is indicated by the arrow $O F_{a c}$ in Fig. 18 . If now an additional single-phase load is thrown on another phase, it will give rise to another single-phase magnetomotive force along a path having a fixed centre line. This in combination with $O F_{a c}$ will in general result in an elliptically-rotating field. The

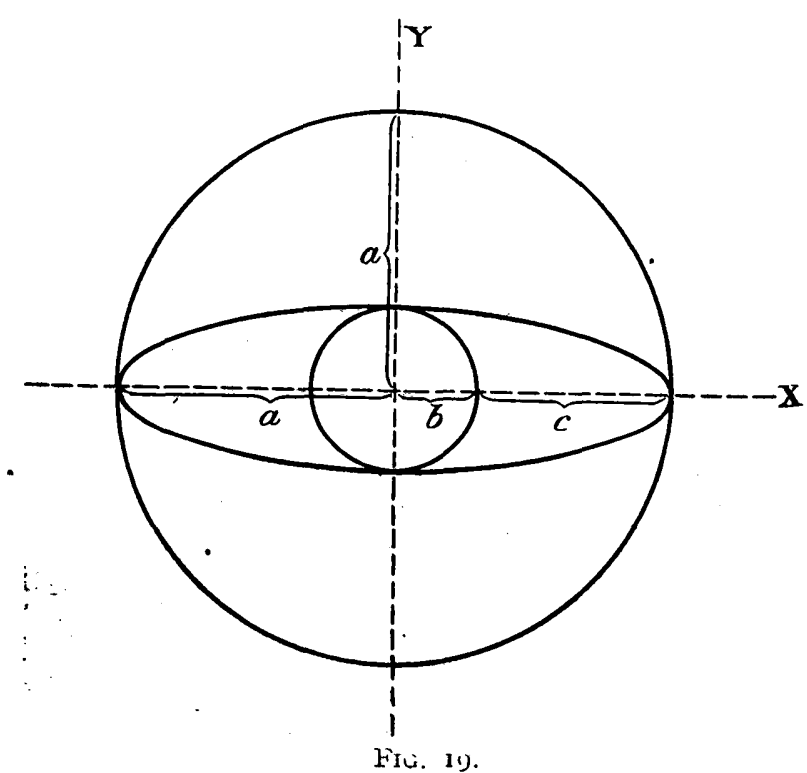

addition of a third magnetomotive force changes the shape of the ellipse. In the special case where the single-phase loads on all phases are equal and have equal angles of lag, the ellipse becomes a circle, and we get a simple rotating field, as stated above.

Consider now the general case of any ellipticallyrotating field. Let the ellipse be that shown in Fig. I9. Whatever be the slope of the major axis with respect to the horizontal line, it is always possible to take our abscissæ $x$ along the major axis and our ordinates $y$ along the minor axis, and to express the curve in the form $x^{2} / a^{2}+y^{2} / b^{2}=\mathrm{I}$, where $a$ and $b$ are the lengths of the major and minor axis respectively. If we now write $a=b+c$, where $c$ can be found in any given case,

$$
\begin{aligned}
\frac{x^{2}}{(b+c)^{2}} & =\cos ^{2} \omega t \text { and } \frac{y^{2}}{b^{2}}=\sin ^{2} \omega t, \\
& x=b \cos \omega t+c \cos \omega t, \\
y & =b \sin \omega t .
\end{aligned}
$$

The elliptically-rotating field can be regarded as consisting of two parts: one part a simple rotating field whose vector is given by the co-ordinates $x_{\mathrm{x}}=b \cos \omega t_{\mathrm{m}}$. $y_{\mathrm{r}}=b \sin \omega t_{s}$ and the other part a single-phase stationary field lying along the major axis of the ellipse, given by. the expression

$$
x_{2}=c \cos \omega t ; y_{2}=0 \text {. }
$$

Now the single-phase field can be broken up into two oppositely-rotating fields :

$$
\begin{aligned}
& x_{2}=x_{4}+x_{5}=\frac{1}{2} c \cos \omega t+\frac{1}{2} c \cos (-\omega t), \\
& y_{2}=y_{4}+y_{5}=\frac{1}{2} c \sin \omega t+\frac{1}{2} c \sin (-\omega t) .
\end{aligned}
$$

Adding $x_{\mathrm{I}}$ to $x_{4}$ and $y_{\mathrm{I}}$ to $y_{4}$, we get :

$$
\begin{aligned}
& x_{6}=x_{1}+x_{4}=\left(b+\frac{1}{2} c\right) \cos \omega t, \\
& y_{6}=y_{1}+y_{4}=\left(b+\frac{1}{2} c\right) \sin \omega t .
\end{aligned}
$$

These form a uniform field rotating forwards, while $x_{5}=\frac{1}{2} c \cos (-\omega t)$ and $y_{5}=\frac{1}{2} c \sin (-\omega t)$ give us a uniform field rotating backwards. Thus we see that the magnetic field produced in a polyphase machine having symmetrically disposed coils carrying an unbalanced load can be regarded as the resultant of two uniform fields of different amplitudes rotating in opposite directions.

In their paper* read before the American Institute of Electrical Engineers, Messrs. Gilman and Fortescue state that "an unbalanced polyphase system can be resolved into two balanced systems of positive and negative phase-rotation." It will be seen that this proposition is much wider than the one stated above with regard to the magnetic field, and does not seem to be established by the "proof" given by the authors. By employing the symbolic method, the authors merely describe in algebraical terms a stationary clock diagram; and because of the limitations of the method they employ they cannot establish the proposition.

For our present purpose, however, the proposition established above concerning the magnetic field produced in a polyphase machine is sufficient for the understanding of methods of phase-balancing consideredi under this heading.

An unbalanced load in a polyphase stator produces a backward-rotating magnetic field in the rotor; and the converse proposition is also true, namely, that a backward-rotating magnetic field in the rotor will produce an unbalanced load in the stator. One way, therefore, of making a balancer for a polyphase system

" "Single-phase Power Service from Central Stations," Transactions of the American Institute of Electrical Engineers, 1916, vol. 35 , p. 1329. 
is to build a synchronous motor having a special winding on the rotor through which currents can be sent which impress a backward-rotating magnetomotive force. The special winding on the rotor in these machines resembles the winding on a slip-ring rotor for an induction motor. The terminals of the winding may be carried either to slip-rings or along the shaft, according as the special auxiliary generator operating as an alternating-current exciter is separate or, rigidly connected to the rotor. Various methods * have been proposed for supplying the double-frequency current that is necessary for producing the backward-rotating field. For instance, an alternating-current generator having twice as many poles as the main machine may have its armature directly connected to the rotor and the connections arranged so as to give the required direction and phase to the rotating field. A change in the strength of the poles of an exciter belonging to this auxiliary generator changes the amount of unbalanced load taken by the balancer. With suitable automatic gear of the Tirrill type the balancer can be made automatic. In another method the armature of the auxiliary generator has the same number of poles as the balancer and is driven at the same speed, but the poles of this generator are fed with three-phase current of the same frequency as the main supply. These three-phase currents (which may be in series with the load) produce a magnetic field rotating in a direction opposite to the direction of rotation of the armature. Thus a doublefrequency current is produced in the winding of the rotor of the balancer which is proportional to the threephase load. All these methods involve the use of several auxiliary machines in addition to the main translating apparatus required to furnish the singlephase load at its right voltage; and in the single-phase furnace projects with which the author was concerned they did not give the characteristics that were required, and were ruled out in favour of the type of balancer falling under heading (5).

(5) A Rotating Balancing Transformer, which absorbs the balanced three-phase power in one winding and supplies a single-phase load from an independent winding.

A balancer of this kind is of special interest in connection with single-phase electric furnaces.

The main advantages claimed for the single-phase furnace are as follows:- In the first place, only two electrodes are required instead of three; and as these can be brought into the furnace at two diametrically opposite points the liability of the arc to cause a shortcircuit through the hot semi-conducting lining is very much reduced. This enables the voltage between the terminals to be raised to a value almost double that which is practicable for a polyphase furnace. The increase in the voltage leads to a corresponding reduction in current for the same power input; the smaller current leads to economy in conducting cables and contacts and enables a much smaller electrode to be used than is possible in the polyphase furnace. As the electrode losses are dependent upon the surface of carbon exposed

* U.S.A. patents Nos. 108,567, 113,454, Ir3,455-6, 113,457 , and $x 17,64 \mathrm{I}$ of 1916 .

VOL. 57. and also upon the amount of air leakage through the furnace, the reduction in the number and size of the electrodes and in the number and size of leakage holes

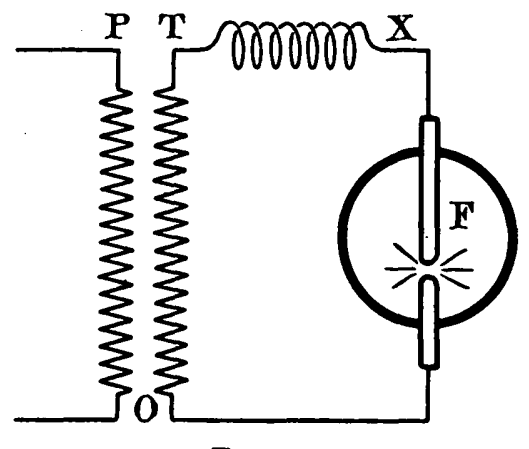

FIG. 20.

results in a great saving in electrode consumption. In the second place, the single-phase furnace has an'

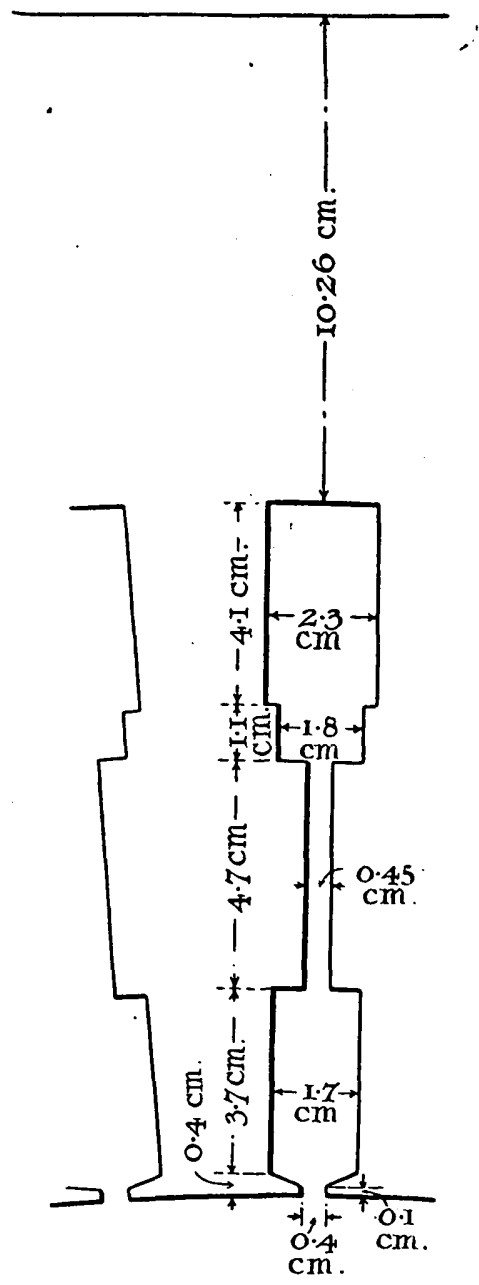

FIG. 2 I.

exterior shape which approaches a spherical form; the radiation losses are thus reduced to the smallest possible for a given content. 
Requirements in balancer for single-phase furnace work. -When the purpose is to supply a single-phase current to an electric furnace, the source of supply being an ordinary three-phase system, there is an advantage in using a special kind of balancer which shall fulfil the functions of (I) voltage transformer, (2) balancer, (3) reactance, and (4) power-factor corrector. These functions can of course be performed by a motorgenerator set designed with suitable characteristics; but the first cost of a motor-generator set is higher than that of a balancer of the same output, and the efficiency is lower. More clearly to understand the functions of such a balancer, something should be said of the advantages (from the user's point of view) of working a single-phase furnace with an inductance in circuit sufficient to make the current lag by $45^{\circ}$ behind the voltage.

Consider the circuit shown in Fig. 20, where O P is the primary winding of a transformer, $\mathrm{O} T$ its secondary winding, $\mathrm{T} \cdot \mathrm{X}$ a choking coil, and $\mathrm{F}$ a single-phase furnace. In the vector diagram, Fig. 22, let $\mathrm{O} T$ represent the

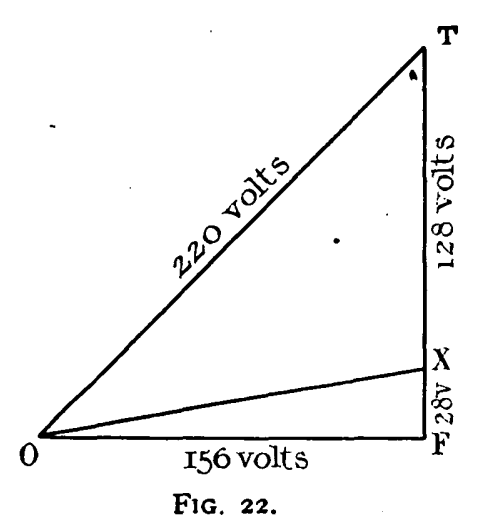

voltage generated by the secondary, $\mathrm{X} T$ the reactive drop in the choke coil (with which may be included any reactive drop in the transformer). Let $\mathrm{F} X$ represent the reactive drop in the furnace, and $O F$ the resistance drop in the furnace and the rest of the circuit. If this diagram represents the full-load working conditions, then the full-load current is lagging $45^{\circ}$ behind the voltage, and is represented to some scale by the line $\mathrm{O} F$. When the inductance and resistance are adjusted to give these conditions on full load, and the inductance is maintained constant, the voltage $\mathrm{O} T$ being constant, the input to the furnace cannot exceed $*$ the full-load value however the resistance of the circuit may be varied. In fact, if we change the resistance of the furnace from infinity to zero, the current will increase from 0 to $I_{4} \mathrm{I}$ times full-load current, and the power at various values of the current will be given by the curve in Fig. 23. The full-load value of the current gives the highest point of the curve. Any reduction of the resistance of the furnace beyond this point causes a decrease in the input, although the current is slightly

$$
\begin{aligned}
& \text { - The proof of this is as follows :- } \\
& \qquad \text { Power }-E I \cos \phi=E \frac{E}{\sqrt{\left(R^{2}+X^{2}\right)}} \cdot \sqrt{V\left(R^{1}+X^{2}\right)}=\frac{E^{2} R}{R^{2} \cdot 1-X^{2}}
\end{aligned}
$$

This is at a maximum when $R=X$. increased. If the furnace is short-circuited, the input falls to zero and the current cannot exceed I. 4 I times full-load current.

The importance of stability.-These conditions give stability in operation, and are of great importance in preserving the lining of the furnace. No really satis- factory refractory substances can be obtained for the lining of electric furnaces. The best commercial substances, such as dolomite, magnesite, or silica brick, have melting-points not very far above the temperature at which it is desired to work the furnace. If by any unfortunate chance part of the lining reaches a temperature above its melting-point, it begins to blend with the contents of the furnace, causing trouble with the pouring and heavy expense in re-lining. Now the maintaining of the furnace at its proper temperature depends upon the maintaining of the balance between the electrical input and the energy absorbed and radiated. If the characteristics of the circuit are such that an increase in the current is accompanied by an increase

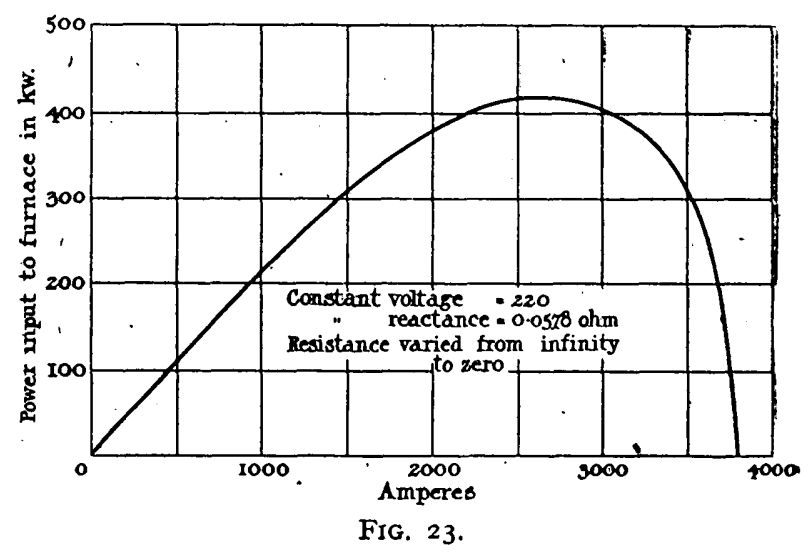

in the electrical input, the greatest care must be exercised, when the furnace is at full load, to keep the current near its full-load value; and this is difficult by reason of the unstable nature of the arc. Automatic regulators are often installed to keep the current within bounds, but even these are not found to be sufficient during the first twenty minutes after the furnace has been started up from the cold; and in some three-phase furnaces, where no great amount of inductance is connected in circuit, it is necessary to have three operators (one at the regulating wheel of each carbon), with their eyes. fixed on the ammeter, to screw up and down the carbons. every few seconds in order to keep the currents approximately balanced. After the furnace has been heated. fairly well, the lengths of its arcs are greater, and the regulating can then be handed over to a regulator of: the Thury type.

Where sufficient inductance is put in series with the furnace, the circuit becomes automatically stable and. no such regulators are required. The ideal condition. for steady running is attained when the inductive drop. at full load is equal to the resistance drop, as shown in Fig. 23. In some cases the transformers that supply the furnace are built in such a way as to have their magnetic leakage great enough to give the required. 
inductive drop. In designing transformers for this purpose, care must be taken to see that the cross-section of any iron added to the leakage paths is sufficiently great to give a fairly straight-line law for the increase of the leakage flux with the current, right up to the point $\mathrm{I}_{4} \mathrm{I}$ times full-load current; otherwise it may be found that when the furnace is short-circuited the current taken is much more than $\mathrm{r}^{\circ} \mathrm{I}$ times full-load current, and trouble nay arise with the power company supplying the three-phase power. A case came to the notice of the author in which failure to provide a sufficient cross-section for the reactive iron resulted in undue disturbances to the power system and great loss of furnace linings.

From the power company's point of view, the inductance is not an unmixed blessing. By reducing the power factor it calls for more copper in the mains for a given load, and reduces the output of the generators.

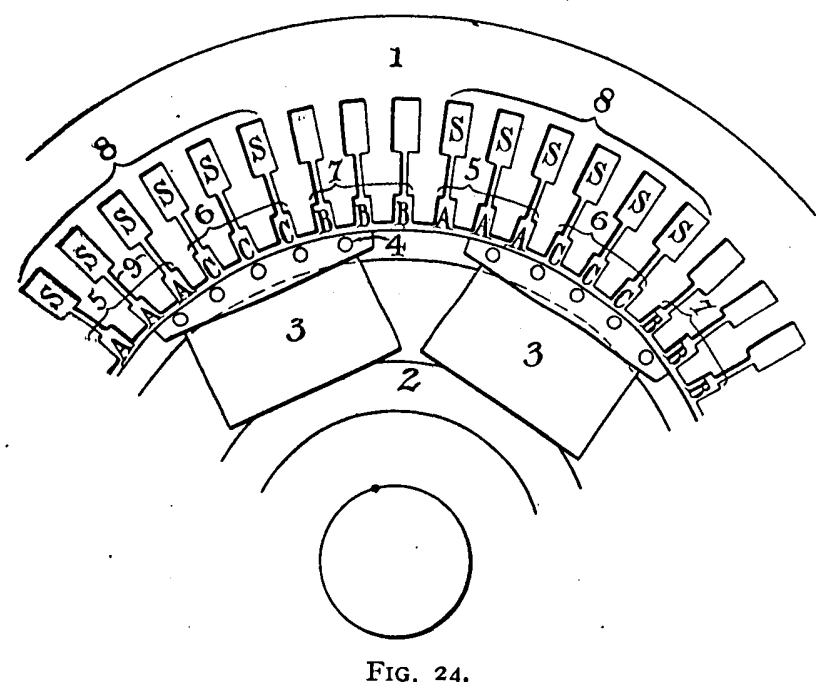

Sudden heavy calls for low-power-factor current have a bad effect upon the regulation of the whole system. But so greatly does the stability given by the inductance help towards economy in furnace linings, that large numbers of furnaces in this country and in America are run at 0.7 power factor. The single-phase furnace, having only one carbon at the top, presents a smaller area of roof lining to the fierce radiation from the arc, and for this and other reasons set out above it is more economical than the three-phase furnace.

Design of balancer for single-phase furnace work.-It will be seen, then, that in designing a balancer to provide a single-phase furnace load from three-phase power mains it is desirable that the single-phase winding should have such a high inductance that the current will lag $45^{\circ}$ at full load. At the same time, it is desirable that the three-phase winding should be operated at unity power factor. These conditions can be met by building a three-phase synchronous motor having an ordinary three-phase armature winding lying in slots near the working face of the stator (see Fig. 24), and provided with a single-phase winding lying in slots further removed from the rotor than the three-phase slots and arranged so that very considerable magnetic leakage occurs between the two windings at full load.

The dimensions of the three-phase slots near the surface of the armature and of the single-phase slot lying in the centre of the punching are shown in Fig. $2 \mathrm{I}$. This figure also shows a narrow slot $0^{\circ} 45 \mathrm{~cm}$. wide, across which the leakage flux finds its way at full load. The calculations here given show bow one can arrive at the characteristics of such a machine. The machine described is one of two designed for the Snyder Electric Furnace Company and now in successful operation in this country. Another, somewhat similar. machine has been designed to be built by the AllisChalmers Company of America, and several machines of larger output are in contemplation. The British machines are required for furnaces to make steel for war purposes.

'In the case of the $400-\mathrm{kw}$. balancer here described, the following were the particulars of the conditions to be met:

Three-phase supply. Line voltage 6,000 at, 50 cycles Input to furnace $\quad \ldots \quad \ldots \quad \ldots \quad 350$ to $400 \mathrm{kw}$

Voltage on arc and connecting cables in phase with the current ${ }_{15}^{6}$

Effective inductive drop in furnace and cables $\ddot{3}$ at terminals $\begin{array}{ccc}\text { Single-phase voltage at terminals } \\ \text { of balancer } \quad . . & \ldots & \ldots\end{array}$ Inductive drop in windings of balancer .. $\quad$.. $\quad$.. $\quad$.. 11 10 to 130 No-load voltage $\quad \ldots \quad \quad \ldots \quad \quad \ldots \quad 220$ to 247 , say 234 Single-phase amperes $\quad \ldots \quad \ldots \quad 2,400$ to 2,700

Temperature rise of balancer after full load for three hours $\cdots 45^{\circ} \mathrm{C}$.

The inductive drop in the furnace was a quantity that could not be given exactly by the makers, and therefore allowance had to be made in the windings of the balancer so that if the inductive voltage came out high a rather higher no-load voltage could be obtained. Arrangements were made so that a no-load voltage of 247 could be obtained if it should be necessary. Before this balancer was completely wound, measurements were made on another furnace, from which it appeared that the inductive drop in furnace and leads would come out at about 28 volts, and that the best relation between the various voltages would be that indicated in Fig. 22.

The method of fixing upon the size of frame and the other dimensions in order to secure the requisite characteristics is given in Appendix VII. The calculation sheet of the machine is given on page 124 .

Compensating winding.-One of the special features of this type of balancer is a compensating winding designed to inject a boosting voltage into the two phases of the three-phase winding that lie adjacent to the single-phase winding, in order to prevent those windings from taking more than their share of the load. If this winding were not provided, phases $A$ and $C$ (adjacent to which the single-phase slots are placed) would take a load equivalent to a single-phase load on the threephase system, by reason of the fact that the magnetic 


\section{3-phase to Single - phase Balancer}

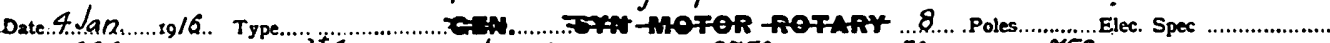

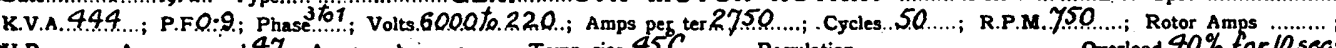

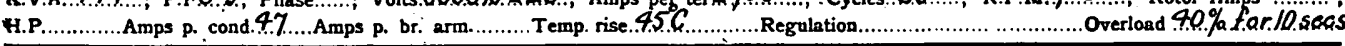

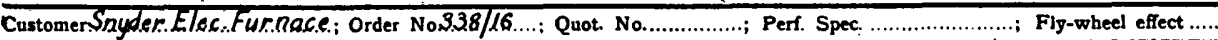

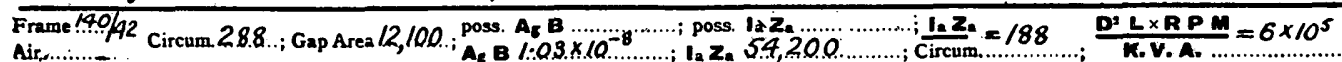

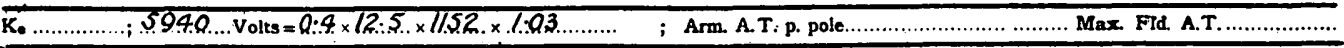

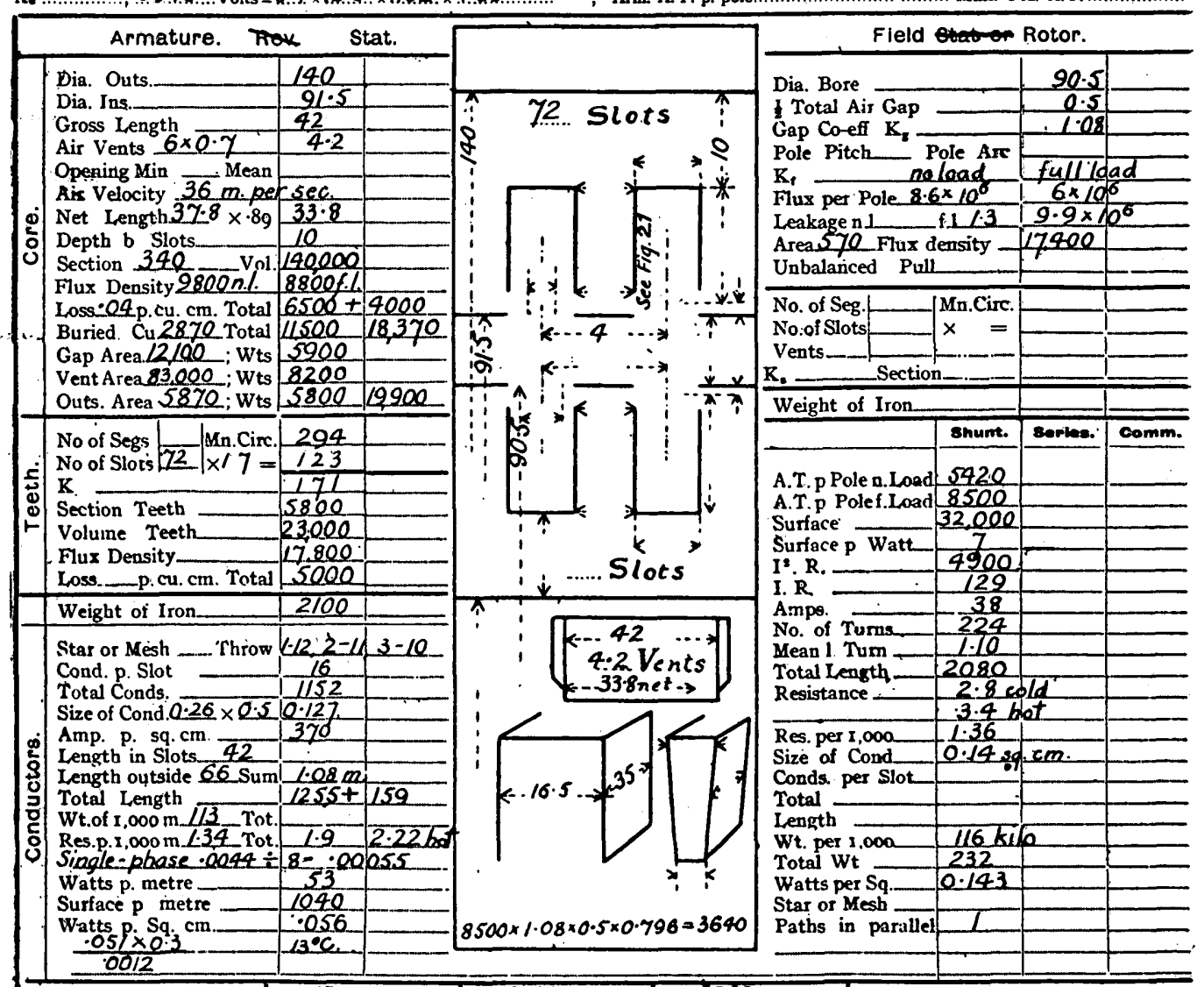

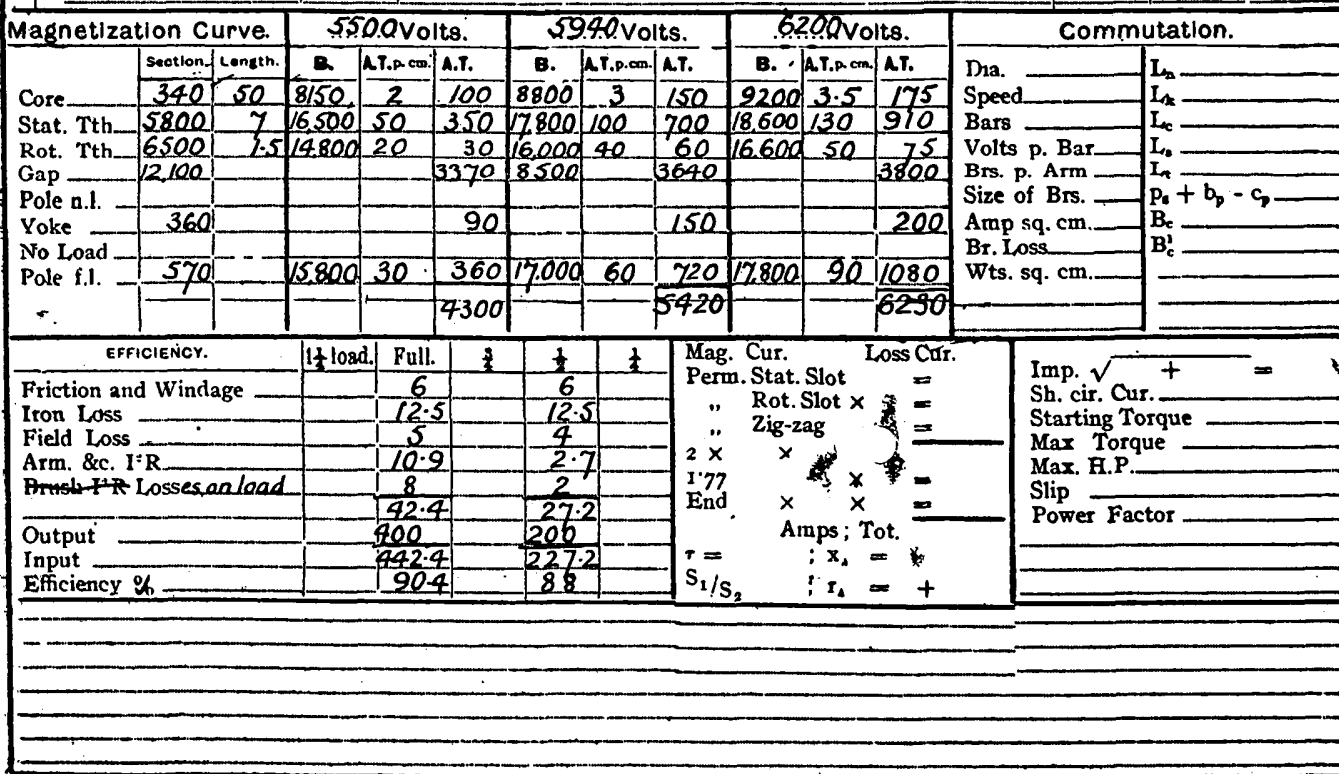


coupling between these phases and the single-phase coils is more complete than the coupling between the single-phase winding and phase B. Another way of looking at the matter is this: When current passes through the single-phase winding, it drives magnetic flux * across the three-phase slots of phases A and C and causes an inductive drop in these phases; so that there will flow from the line a current of such value and of such phase that it produces an impedance rise sufficient to balance the inductive drop produced by the single-phase magnetomotive force. Since the resistance drop is small, compared with the reactive drop, the excess current that would be taken by phases $A$ and $C$ would be almost in exact opposition of phase to the single-phase current.

One way of preventing this action is to inject into phases $\mathrm{A}$ and $\mathrm{C}$ an electromotive force which shall at all times be exactly equal and opposite to the electromotive force generated in the three-phase winding by the interlinked flux from the single-phase magnetomotive force. The most direct way of doing this is to wind a few turns of wire interlinked with the main leakage path of the single-phase winding, and electrically connect these to phases A

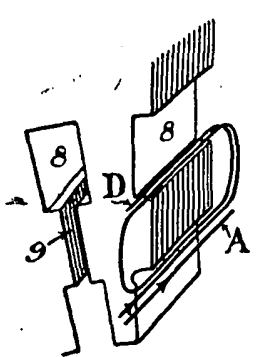

FiG. 25.

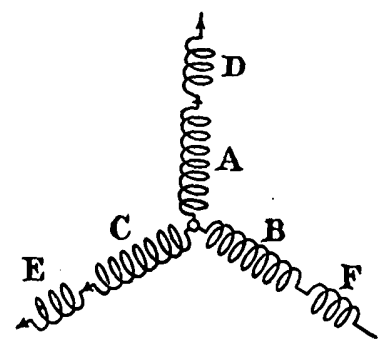

Frg. 26. and $C$ so that the E.M.F. generated in the turns by the main leakage shall oppose the E.M.F. generated in the three-phase winding by the small leakage across the three-phase slots. As the leakage flux across the leakage air-gap is great, compared with the leakage across the three-phase slots, only very few turns of compensating winding are required to balance the E.M.F. in the 16 conductors per slot of the three-phase winding. The counter magnetomotive force set up by these few turns is so small, compared with the magnetomotive force of the single-phase winding, that it can be neglected in roughly estimating the number of compensating turns required. In Appendix VIII is given the method of calculating the number of compensating turns required. The manner of winding and connecting the compensating conductors can be seen from Figs. 25 and 26.

Tappings on the three-phase winding.-In order to provide a means of making small adjustments in the balance of the load on the three-phase winding after the machine was built, three tappings were taken off each of the phases near the star point. These were at 3,6 ,

- It should be noted that any change which occurs in the field flux due to the single-phase load (except in so far as it is exterior to the damper) affects phase $B$ as much as phases $A$ and $C$. and 9 turns respectively away from the inner end of each phase. As there are I92 turns per phase, the tappings give a choice of cutting out $1{ }^{\circ} 6$ per cent, 3.12 per cent, or 4.68 per cent of the phase voltage. In practice it was found that the connection that gave the best result with only 3 compensating turns connected was that shown in Fig. 27. The effect of this slight dissymmetry in the connections was to give a slight dissymmetry at no load, as shown by the figures on page i 13 . This dissymmetry is of no importance in practice, and can be eliminated in future by a better adjustment of the compensating winding. When there is no load on the single-phase winding, there is no E.M.F. in the compensating winding; ${ }^{*}$ and as it is the same magnetomotive force that operates upon the compensating winding as operates upon the three-phase winding and creates a tendency to unequal back E.M.F., the right adjustment of the compensating winding should bring about a nearly exact balance of the phases. The currents in the damper on the field poles also tend to

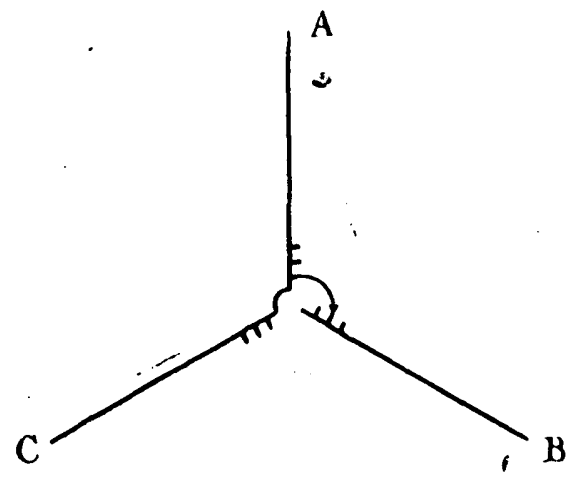

Fig. 27.

create a disturbance in the balance of the load; this disturbance is of a very complex nature, but fortunately is not of very great moment.

The damper on the field poles.-The damper consists of 9 drawn copper bars of taper section. These are held in dovetail slots in the pole face. and pinned and sweated to a copper casting encircling each pole. The copper castings are bolted together from pole to pole so as to form a complete squirrel-cage winding. In order to avoid any inductive action between the individual stator slots and the bars of the damper, the slots on the field poles are skewed through a complete stator slot pitch. It was found that with this arrangement the damper showed no signs of heating at no load, and only very slight heating at full load. On a previous machine in which this precaution was not taken, there was a considerable loss in the damper at no load, owing to the inductor action of the stator teeth.

General method of design.-Apart from the special features above mentioned, the design of the balancer follows very closely the design of an alternating-current generator or synchronous motor. The full details of ar:* Except a very small inductive drop due to the three-phase load, which Cx:* Except a very small inductive drop due to the three-phase load,
can be compensated for by the addition of a small choke coil in phase $B$. 
MESSRS. SANDYCROFT; I,TD.

Test SheET.

Date, 15 March, I9I\%.

No-load Losses.

For Snyder Filectric Furnace Company.

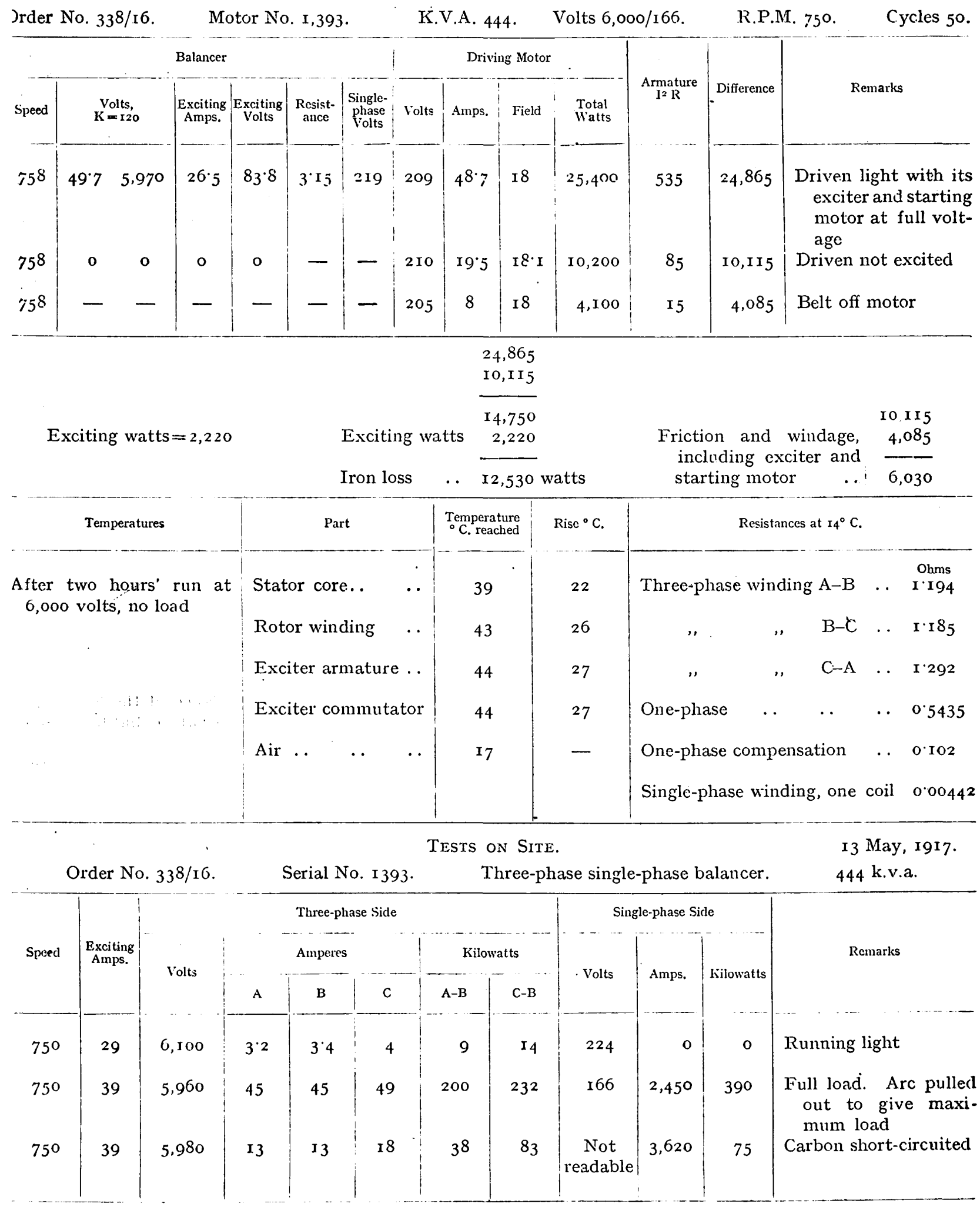


the design are given in the calculation sheet on page I24. It is unnecessary here to do more than supplement the explanation given in the author's book of the general method of design.

Ampere-turns on the field magnet.-These are calculated in Appendix IX.

Heating and cooling of the frame.-The calculation of the heat generated at full load follows the rules given in the book referred to, except that on this machine one has the copper losses of two armatures, and rather heavier eddy-current losses in end plates than on simple generators of the same size. As against this, the airgaps provided in the leakage path around the singlephase winding afford a very effective cooling surface not found in ordinary machines. This can only be utilized well if an efficient fan is provided to blow a very positive blast of air through the ventilating ducts. The machine was accordingly built with end bells designed so. as to enclose the air from the fan blades on the field magnet and to compel a great part of it to traverse the ventilating ducts, while the remainder passed over and between the armature coils before it escaped at ducts provided at the periphery of the end bells.

Armature losses.-The various losses and the manner in which the heat is carried away are given in Appendix $\mathrm{X}$.

Efficiency.-The measured friction and windage, iron and field losses are filled in their respective places on the calculation sheet. In addition to these losses, an allowance of $8 \mathrm{kw}$, has been made for extraneous loss at full load, bringing up the total losses at full load to $4^{2} .4 \mathrm{kw}$. Thus the efficiency works out at $90^{\circ} 4$ per cent. So far as could be ascertained from measurements made on integrating meters over a number of runs on the furnace, this figure is very near the mark.

Tests.-It was not possible to make a load test at the maker's works, for sufficient power was not available. Particulars of the no-load tests are given on page 126 .

The full-load test was made after the machine had been delivered to the works of Messrs. Summerson, Ltd., Darlington. Characteristic figures of the test are given on page $\mathrm{I} 26$. It will be seen that when running light there is a dissymmetry in the power taken by - different phases: this is due to the arrangement of taps shown in Fig. 27, but does not cause any measurable interference with the voltage at the end of a long feeder. When the furnace is in circuit, the amount of load can be varied slightly by altering the distance between the electrodes. The point of maximum load is in practice found by trial. Any increase or decrease of the length of the arc from this maximum-load point causes a decrease in the load. It is sometimes convenient to vary the load by changing the length of the arc, but the steadiest conditions are obtained when the arc is on the maximum-load point. It will be seen that the balance of the load is quite good, the currents in the three lines $\mathrm{A}, \mathrm{B}$, and $\mathrm{C}$ being 45,45 , and 49 amperes respectively. The deviation from the perfect balance is not more than is often found on standard polyphase machines.

Short-circuit conditions.-A very interesting experiment is to screw down the top carbon until it dips into the metal in the furnace. As the arc is shortened, the voltage falls; when the carbon is in contact with the metal the voltage cannot be read on the voltmeter and the watts fall to a small amount of the order of $75 \mathrm{kw}$., depending upon the condition of the charge. The current rises to somewhere between 3,500 and 3,800 amperes. The load on the three-phase side falls to about I2I kw. This is satisfactory from the power company's point of view.

- The author wishes to express his thanks to the Snyder Electric Furnace Company for permission to publish the figures given in the paper, to Messrs. Sandycroft, Ltd., for supplying data of the balancer, and to $\mathrm{Mr}$. J. A. Kuyser for the values of the voltage drop in each phase of a three-phase generator, given below.

\section{APPENDIX I.}

Single-phase Load on Three-phase Generator.

The following figures were obtained from a test on an 8,00o-k.v.a. star-connected three-phase generator, which was loaded up on another generator running as a synchronous motor so that the power factor of the load could be adjusted to zero. Measurements were made of the voltage on each leg of the star from the terminals to the star point, as well as between the terminals. The phases will be lettered $A, B$, and $C$ in order of rotation. A single-phase load of 700 amperes at zero power factor was thrown upon terminals $B$ and $C$. The voltages then were:

$\begin{array}{lcccc} & & \text { A } & \text { B } & \text { C } \\ \text { Plhase voltage } & \ldots & 4,130 & 3,950 & 3,820 \\ & & \dot{A}-\mathrm{B} & \text { B-C } & \text { C-A } \\ \text { Terminal voltage } & \ldots & 7, \mathbf{1} 5^{\circ} & 6,600 & 6,95^{\circ}\end{array}$

It is very commonly found on three-phase machincs that the phase voltages are increased by higher harmonics, so that if a diagram is made with the three phase voltages as vectors radiating from a point, and with the three terminal voltages forming the sides of a triangle, the centre point of the star forms the apex of a low tetrahedron, the altitude of the apex depending upon the amplitude of the harmonics. Notably when the phase voltage contains a pronounced third harmonic, which is absent on the terminal voltage, the altitude of the pyramid will be considerable. In this machine each phase winding was short-chorded by $60^{\circ}$, so that it occupied a virtual coil-width of $120^{\circ}$. This had the effect of eliminating the third and ninth harmonics in the phase E.M.F. wave. The winding factor of the fifth harmonic was only about $0 \cdot 165$, and that of the seventh harmonic $0 \cdot 118 . *$ The excess of higher harmonics in the wave-form of the phase voltage over those in the terminal voltage appears to have been of very small value, because we find, when we set out the vector diagram with the voltages given above, that the apex of the pyramid has such a small altitude that the diagram may be * S. P. SMith and R. H. Bouldivg : Journal I.E.E., I915, vol. 53, p. 205. 
regarded for practical purposes as lying in a plane (see Fig. 28). This clock diagram is supposed to revolve in an anti-clockwise direction, and the senses of the

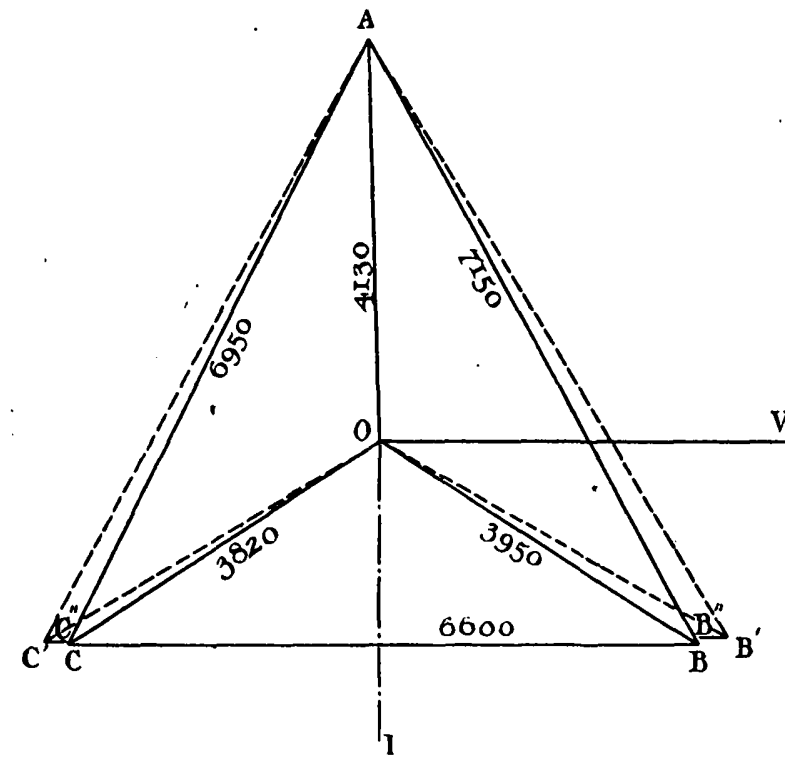

Fig. 28.

vectors must be taken with reference to Fig. 29, in which the arrow-heads show the directions taken as positive in each wire. Particular regard must be had to the direction of the current taken as positive through theory of voltage drop in generator windings. The true reactive drop in the winding appears to have been about 7 per cent of the terminal voltage. This figure agrees very well with the value obtained by the shortcircuit test on the same generator. The resistance

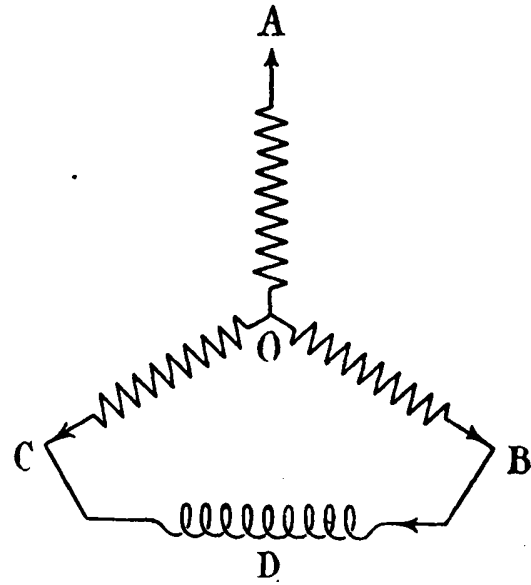

Fig. 29.

drop was only 0.375 of I per cent, and is almost negligible.

In Fig. 28 the author has set out the terminal voltage of $\mathrm{B}-\mathrm{C}$ as the radiating vector $\mathrm{OV}$, and the current of 700 amperes as the vector $O I$ lagging $90^{\circ}$. If we now assume that at no load the voltage in.phase $B$ was 4,130 and occupied position $\mathrm{O} \mathrm{B}^{\prime}$, making an angle

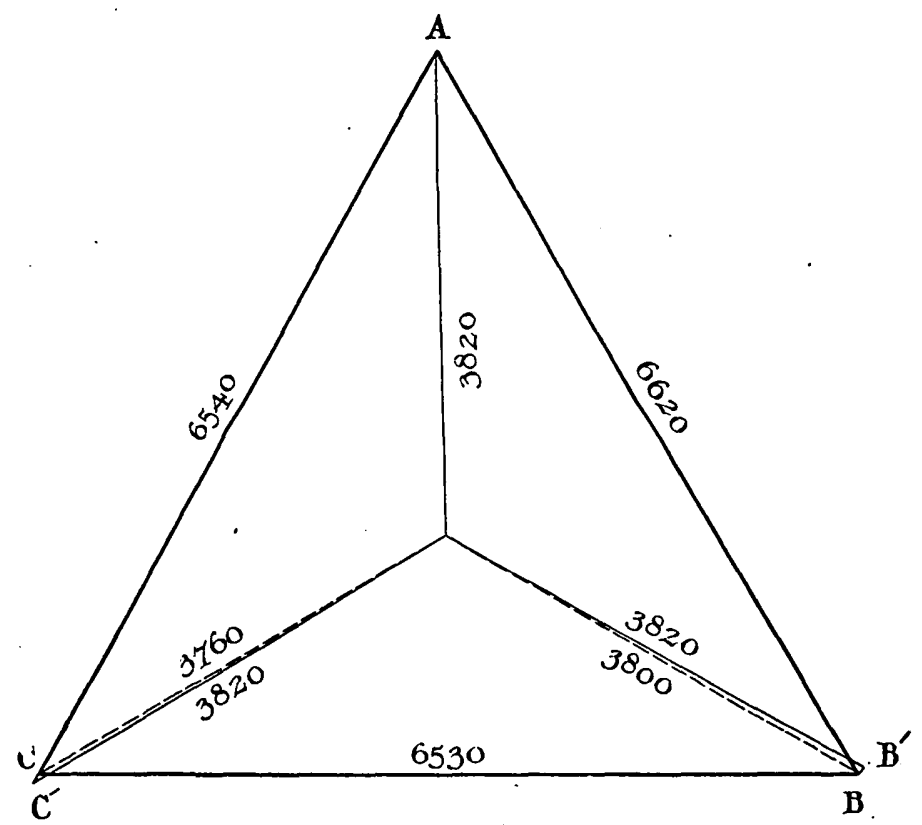

FIG. 30.

the single-phase load $D$. The vectors representing the voltages $B$ and $C$ are only $I 16^{\circ}$ apart. The values of the voltages, and the angle between them, seem to be sufficiently well accounted for by the ordinary of $120^{\circ}$ with $\mathrm{OA}$, and that the phase voltage in $\mathrm{C}$ was also 4,130 volts and occupied position $\mathrm{OC}^{\prime}$, also at $120^{\circ}$ from $\mathrm{OA}$, we see that the allowance of an inductive drop of 7 per cent in windings $B$ and $C$, as 
shown by the vectors $B^{\prime} B^{\prime \prime}$ and $C^{\prime} C^{\prime \prime}$, brings us almost exactly on $B$ and $C$, as ascertained by actual measurements.

It will be noticed that the vector $C^{\prime} C^{\prime \prime}$ is taken in the sense opposite to that of $\mathrm{B}^{\prime} \mathrm{B}^{\prime \prime}$; this is because the current $\mathrm{OI}$ is drawn on the convention that the arrow-head on OC (Fig. 29) is the positive direction along that wire. If then we are to draw the vector $\mathrm{C}^{\prime} \mathrm{C}^{\prime \prime}$ on the convention that the arrow-head on $\mathrm{OC}$ is the positive direction along the circuit, it must be set out in the sense shown in Fig. 28.

From the fact that the construction shown in Fig. 28 gives us so very nearly the figures obtained on test, we can apply a similar construction for obtaining the displacement of voltage caused by a single-phase load, which forms a small proportion of the full-load rating of the machine, and at power factors higher than zero. If, for instance, we put upon the 8,00ok.v.a. 6,600-volt generator a load of only 140 amperes at a power factor of $0 \%$, we obtain a clock diagram (as shown in Fig. 30) in which the disturbances in the voltages of the system are as indicated in the following table :

$\begin{array}{lcccc} & & \text { A } & \text { B } & \text { C } \\ \text { Phase voltage } & \ldots & 3,820 & 3,800 & 3,760 \\ & & \text { A-B } & \text { B-C } & \text { C-A } \\ \text { Terminal voltage } & \ldots & 6,620 & 6,530 & 6,54^{\circ}\end{array}$

We see from this that wherc a single-phase load forms only a small part (say not more than 20 per cent) of the total load on a three-phase station, it may be thrown directly upon one of the phases of a three-phase generator without causing a serious want of balance on the three-phase system. An instance of this kind is found at Bradford, where single-phase furnaces of $400-\mathrm{kw}$. capacity are thrown on and off polyphase mains without causing a noticeable unbalancing of the voltages.

Single-phase armature reaction.-The ratio of the field amperes on three-phase short-circuit (700 amperes pcr phase) to the field amperes on no load was 0.705 on the 8,00o-k.v.a. generator referred to above. When the single-phase short-circuit current of 700 amperes was put upon phase B-C, the ratio of the field amperes on single-phase short-circuit to the field amperes at no load was $0 \cdot 46$. It is generally found that the field ampere-turns on single-phase short-circuit are from 0.65 to 0.75 of the field ampere-turns on three-phase short-circuit, for the same armature current per phase. The exact value of this ratio depends upon the width of the pole arc and upon the efficiency of theamortisseur. Machines having a cylindrical field magnet distributed according to the ordinary plan, and having a very effective amortisseur, have a ratio in the neighbourhood of 0.65 .

\section{APPENDIX II.}

Elimination of the Single-phase Power Component without Obtaining a Balance of Phases.

Let the current in the lines $A, B$, and $C$ be

$$
\begin{aligned}
& i_{a}=\text { I00 } \sin \omega t, \\
& i_{b}=75^{\circ} 4 \sin \left(\omega t-\mathrm{II} 5^{\circ}\right),
\end{aligned}
$$$$
i_{c}=96.6 \sin \left(\omega t-225^{\circ}\right) \text {. (See Fig. } 3^{\mathrm{I}} \text {.) }
$$

The three vectors representing these currents form. the sides of a triangle with the arrow-heads shown in Fig. 32 running concurrently. This is therefore a

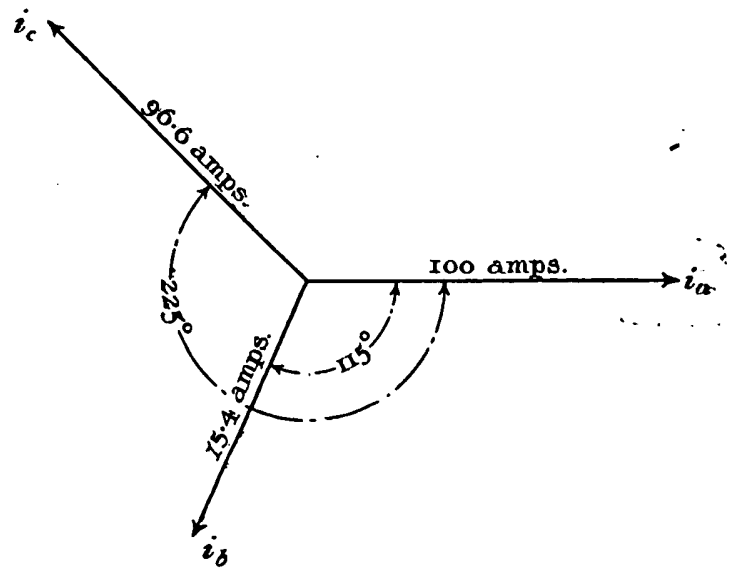

FIg. 31.

possible current distribution in a star-connected system Now let the voltages in the three legs be

$$
\begin{aligned}
& e_{a}=100 \sin \omega t, \\
& e_{b}=206 \cdot 2 \sin \left(\omega t-115^{\circ}\right), \\
& e_{c}=123.3 \sin \left(\omega t-225^{\circ}\right) .
\end{aligned}
$$

Multiplying out $e_{a} i_{a}, e_{b} i_{b}$, and $e_{c} i_{c}$, we find that the alternating components of the power come out:

$$
\begin{aligned}
& 5,000 \cos 2 \omega t, \\
& 7,780 \cos \left(2 \omega t-230^{\circ}\right),
\end{aligned}
$$

and $\quad 5,960 \cos \left(2 \omega t-45^{\circ}\right)$, or $5,960 \cos \left(2 \omega t-90^{\circ}\right)$.

The three vectors representing. these alternating: components form the sides of a triangle with the arrow-heads shown in Fig. 2 following concurrently. Their vector sum is therefore zero; that is to say,

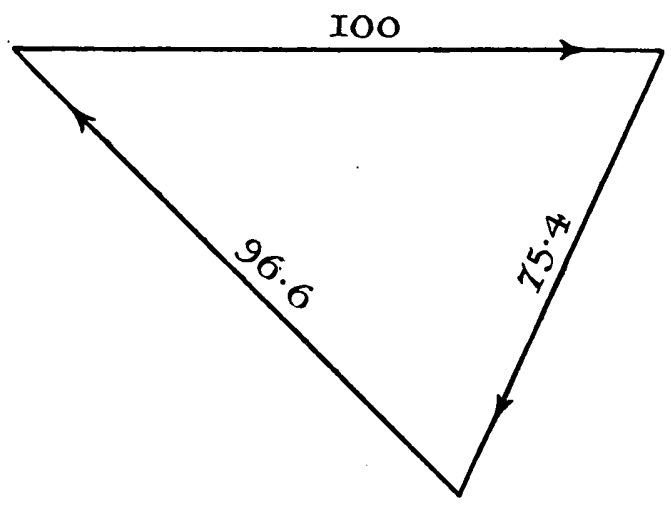

FIg. 32.

the load on the system is balanced according to Steinmetz's definition of bajlance, although the conditions ( $x$ ) and (3) mentioned on page III are far from being met. We thus see that the definitions of balance given. in pages III and II 2 are not necessarily the same. If a system complies with conditions (I), (2) (3), andi 
$\therefore(4)$, then it will be balanced according to Steinmetz's definition; that is to say, the sum of all the alternating components of the power is zero. But it does not follow that if the sum of all the alternating compoments of power is equal to zero the conditions (I), (2), (3), and (4) are also met.

\section{APPENDIX III.}

Graphic Construction showing Balance of Power and Balance of Phases by Means of a ChokeCOIL.

Let the three-phase system A, B, C, Fig. 33, be loaded * with a resistance and choke-coil between the terminals $A-B$. Let the voltages in $A, B$, and $C$ respectively be represented by the vectors $\mathrm{E}_{a}, \mathrm{E}_{b}$, and $\mathrm{E}_{c}$ in Fig. 34 . Taking $e_{a}=\mathrm{E} \sin \omega t$, we have

$$
e_{a b}=\sqrt{ } 3 \mathrm{E} \sin (\omega t+\pi / 6) .
$$

First let us take the instance quoted by Steinmetz $\dagger$ where the power factor of the current A B is such that the current lags $\pi / 6=\phi$ behind the voltage, so that

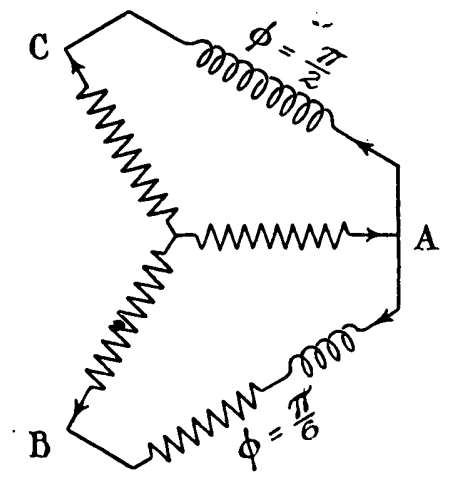

FIG. 33.

$i_{i b}=I \sin \omega t$. The alternating component of the power will be :

$$
\begin{aligned}
& \frac{1}{2} \sqrt{ } 3 \mathrm{E} I \cos \left(2 \omega t+\frac{1}{3} \pi-\pi / 6\right), \\
= & \frac{1}{2} \sqrt{ } 3 \mathrm{E} I \cos (2 \omega t+\pi / 6) .
\end{aligned}
$$

In order to neutralize this alternating component, we can put in circuit a choke-coil fed by a voltage

$$
e^{\prime}=\sqrt{ } 3 \mathrm{E}^{\prime} \sin (\omega t+\pi / 6-\beta)=\sqrt{ } 3 \mathrm{E} \sin (\omega t-\pi / \theta)
$$

where $\dot{\beta}=\frac{1}{2} \phi+\frac{1}{1} \pi=\pi / 12+\frac{1}{4} \pi=\frac{1}{3} \pi$.

This.voltage can be obtained from the terminals A-C, as is shown in Fig. 33, lagging $30^{\circ}$ behind $E_{a}$.

The current through the choke coil is

$$
i^{\prime}=\mathrm{I}^{\prime} \sin \left(\omega t-\pi / 6-\frac{1}{2} \pi\right),
$$

- The example given here is the one given by Steinmetz (ibid., page 326 ). The author shows in Fig. 34 how in this particular instance the phases are are not balanced, although the single-phase load is on the whole eliminated. t Ibid., p. 327 . and if the reactance of the coil be suitably adjusted so that $I^{\prime}=I$, then the alternating component of the power in the choke circuit is

$$
e^{\prime} i^{\prime}=\frac{1}{2} \sqrt{ } 3 E^{\prime} I^{\prime} \cos \left(2 \omega t-\frac{1}{3} \pi-\frac{1}{2} \pi\right),
$$

and as $\cos (2 \omega t-5 \pi / 6)=-\cos (2 \omega t+\pi / 6)$ the two alternating components neutralize one another. Now in this special case it will be seen from Figs. 33 and 34, taking the direction shown by the arrow-heads as positive in each leg, that before the choke-coil was added the current in leg $\mathrm{A}$ was $\mathrm{I}_{a b}$, and in leg $\mathrm{B}$ it was $\mathrm{I}_{b a}$. After the choke-coil is put in circuit the current

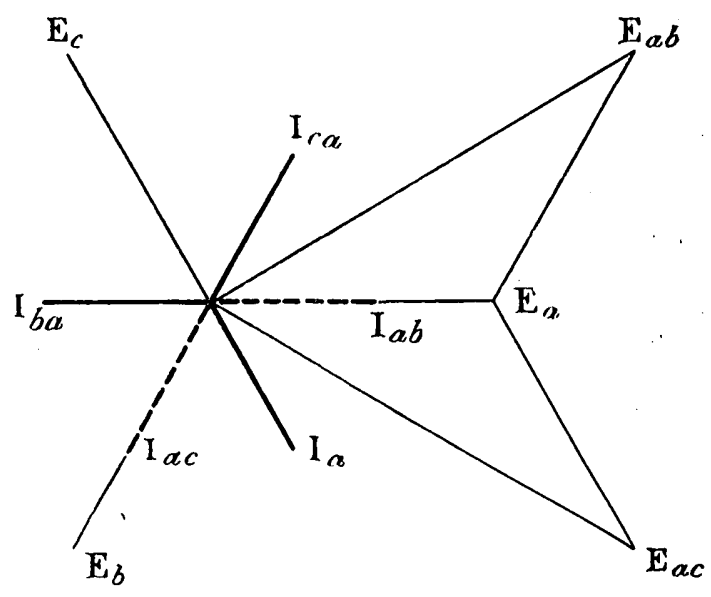

FIG. 34 .

through it is $\mathrm{J}_{a c}$ in leg $\mathrm{A}$, and $\mathrm{I}_{c a}$ in leg $\mathrm{C}$. Adding together $I_{a b}$ and $I_{a c}$, we get $I_{a}$ as the current in $A$. Thus we see that the three legs carry equal currents at $120^{\circ}$ apart; and as the voltages were assumed in balance we see that conditions (I), (2), (3), and (4) hold.

\section{APPENDIX IV.}

Choke-coil Balancer giving Balance of Power. without Balance of Phases.

In applying Steinnetz's method to the case of singlephase load, power factor 0.7 , the question whether or not we get balanced currents depends upon the way in which we build up the voltage $E^{\prime} \sin (\omega t-\beta)$ from the components selected from the three phases. Iet the voltages in the three legs of the star be:

$$
\begin{aligned}
& e_{a}=\mathrm{I}, 000 \sin \omega t \\
& e_{b}=\mathrm{I}, 000 \sin \left(\omega t-\mathrm{I} 20^{\circ}\right), \\
& e_{c}=\mathrm{I}, 000 \sin \left(\omega t-240^{\circ}\right) .{ }^{*}
\end{aligned}
$$

These are shown in Fig. 35 by the vectors $\mathrm{E}_{a}, \mathrm{E}_{b}$, and

* The expression of angles of lag in degrees instead of in radians is adopted for general convenience in what follows. The maximum voltage is arbitrarily 
$\mathbf{E}_{c}$ respectively. Let the single-phase load be fed from terminals $\mathrm{A}$ and $\mathrm{C}$.

$e_{a c}=1,732 \sin \left(\omega t-30^{\circ}\right)$ (see vector $\mathrm{E}_{a c}$ ), $i_{a c}=\mathrm{I}, 000 \sin \left(\omega t-30^{\circ}-45^{\circ}\right)$ (see vector $\mathrm{I}_{\mathrm{S}}$ ). preserve their ratio of transformation and take their proper load, it is necessary (with this method) to carry a fourth wire to the star point of the generator; because the vector sum of the three currents is not equal to zero. If we put in circuit with these second-

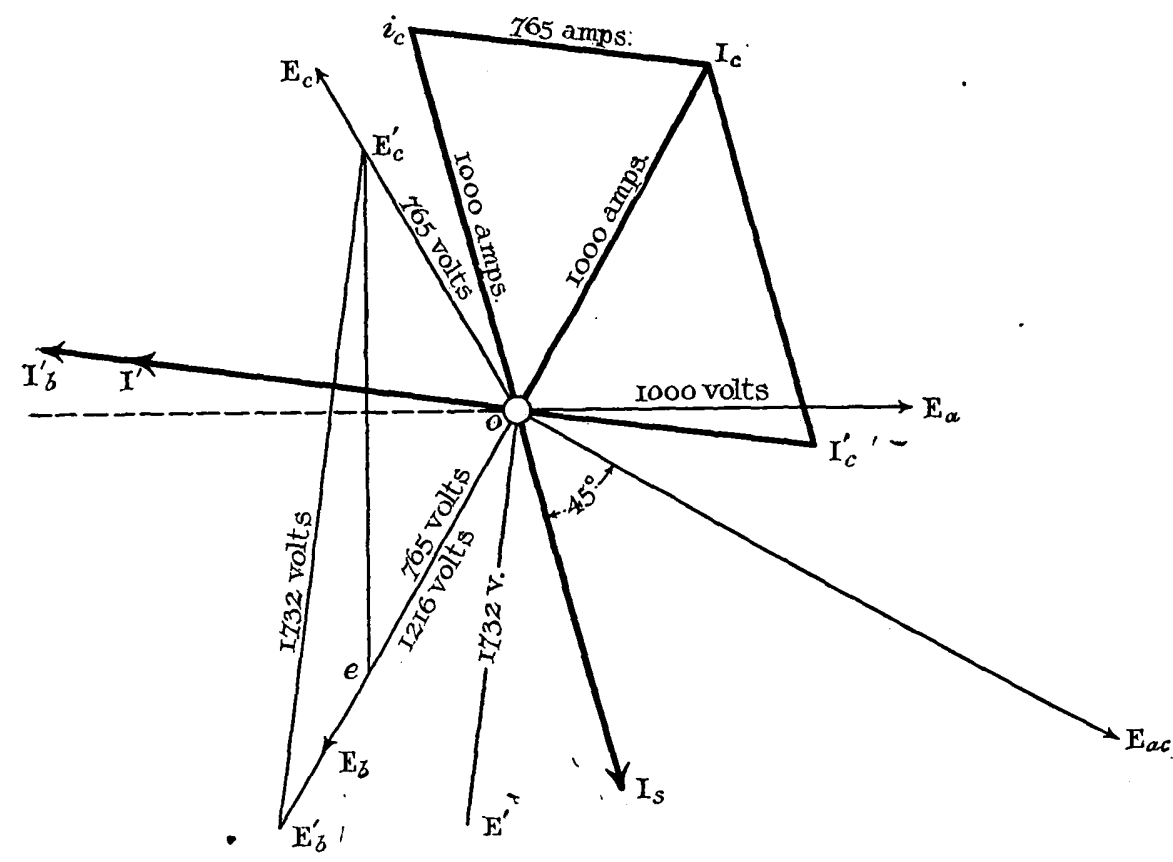

Fig. 35.

As the arrow-head indicating the positive way through the single-phase load is opposite in sense to the arrowhead on phase $C$ (Fig. 8), the vector $\mathrm{OI}_{\mathrm{S}}$ must be reversed (see $\mathrm{O} i_{c}$ ) to represent the current in phase $\mathrm{C}$.

The alternating component of the power is

$$
-\frac{1}{2} \times I, 732,000 \cos \left(2 \omega t-60^{\circ}-45^{\circ}\right) \text {. }
$$

In order to nentralize this alternating component by means of a reactive load, we must make

$$
\beta=\frac{1}{2} \phi+\frac{1}{4} \pi=22 \cdot 5^{\circ}+45^{\circ}=67.5^{\circ} .
$$

Take $e^{\prime}=1,732 \sin \left(\omega t-30^{\circ}-67.5^{\circ}\right)$ (see vector $\left.\mathrm{E}_{c} \mathrm{E}_{b}^{\prime}\right)$, $i^{\prime}=\mathrm{I}, 000 \sin \left(\omega^{\prime} t-30^{\circ}-67 \cdot 5^{\circ}-90^{\circ}\right)$ (see vector $\left.I^{\prime}\right)$.

There are many different ways in which we can produce the voltage $e^{\prime}$. First let us take two transformers, one having a ratio of $x, 000$ to 765 connected across $e_{c}$, and another having a ratio of $\mathrm{I}, 000$ to $\mathrm{I}, 2 \mathrm{I} 6$ connected across $e_{b}$. If the secondaries of these are connected so as to give the resultant

$$
\text { I,2I.6 } e_{b}-\frac{765}{\mathrm{I}, 0000} e_{c}
$$

we shall get the vector $\mathrm{E}_{c}^{\prime} \mathrm{E}_{b}^{\prime}$ of right phase and right amplitude. In order that these transformers may aries a reactive coil of negligible resistance having a reactance of $\mathrm{I} \cdot 732 \mathrm{ohms}$, so that it takes the current

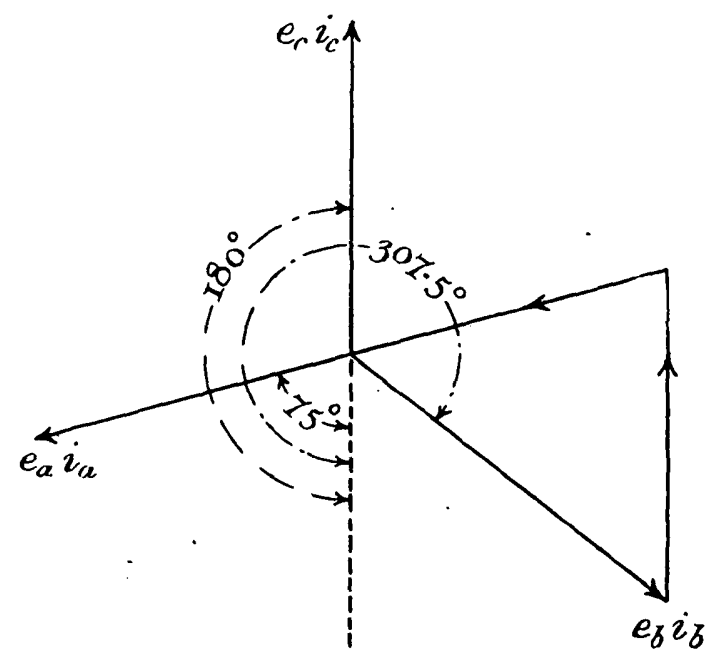

FIG. 36 .

$\mathrm{I}^{\prime}$ having a maximum of $\mathrm{I}, 000$ amperes, it will be found that the alternating components of the power will balance out. When 1,000 amperes flow through 
the secondary in phase $C$, the current in the primary will be $76_{5}$ (shown by the vector $\mathrm{OI}_{c}^{\prime}$ ); and the current in the primary of phase $B$ will be 1,216 amperes (shown by the vector $O I_{b}^{\prime}$ ). The vector representing the current of the original single-phase current in phase $C$ is $O i_{c}$. To this add $\mathrm{I}_{c}^{\prime}$, and obtain $O \mathrm{I}_{c}$, the total current in $C$. We now see that the three currents $I_{S}, I_{b}^{\prime}$, and $I_{c}$ are unbalanced and do not form a closed triangle, so that they cannot flow without the assistance of a fourth wire. Their values are :

$$
\begin{aligned}
& i_{a}=\mathrm{I}, 000 \sin \left(\omega t-75^{\circ}\right), \\
& i_{b}=\mathrm{I}, 2 \mathrm{I} 6 \sin \left(\omega t-\mathrm{1} 20^{\circ}-675^{\circ}\right), \\
& i_{c}=\mathrm{I}, 000 \sin \left(\omega t-240^{\circ}-60^{\circ}\right) .
\end{aligned}
$$

Nevertheless the alternating components of the power taken in all phases balance one another out. This is seen from Fig. 36 , which is a clock diagram of the

\section{APPENDIX $V$.}

Method of Choosing the Component Voltages from the Three Phases in Order to Build UP $E^{\prime} \operatorname{Sin}(\omega t-\beta)$ so as to Get Balanced CuRRENTS IN THE CASE OF A CHOKE-COIL BALANCER.

The triangle $\mathrm{J}_{b}^{\prime} \mathrm{OJ}_{c}$ (Fig. 37 ) is intended to be the triangle whose sides shall represent the final resultant currents in phases $A, B$, and $C$. The base $I_{b}^{\prime} O$ is necessarily parallel to $I^{\prime}$ and lags $75^{\circ}$ behind the vector $O \mathrm{E}_{a}$. The vector $\mathrm{OI}_{c}$ is made up of $\mathrm{O} i_{c}$, which is known, and $i_{c} \mathrm{I}_{c}$, whose direction is known, namely that of $O \mathrm{I}_{c}^{\prime}$, the current in the primary of the transformer in: leg $C$. The current in the primary of the transformer: in leg $\mathrm{B}$ is $\mathrm{I}_{b}^{\prime} \mathrm{O}$. The current in $\mathrm{A}$ is $\mathrm{I}_{c} \mathrm{I}_{r}^{\prime}$, which is made up of the single-phase current $I_{S}$ plus the transformer primary current $\mathrm{I}_{c}^{\prime} \mathrm{I}_{b}^{\prime}$; and in order that the

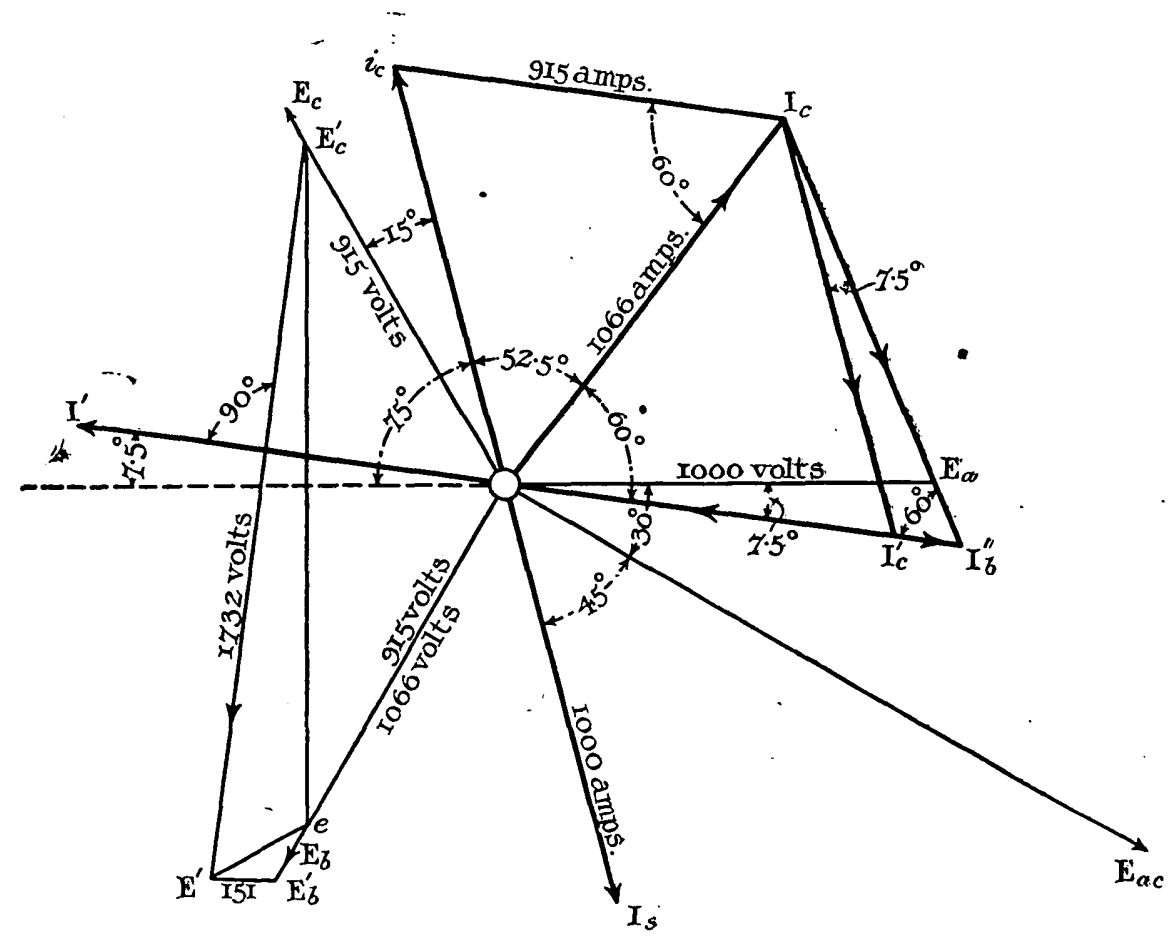

F1G. 37.

double-frequency vectors obtained by taking the alternating components of the products $e_{a} i_{a}, e_{b} i_{b}$, and $e_{c} i_{c}$. These are :

and

$$
\begin{aligned}
& \frac{1}{2} \times 1,000,000 \cos \left(2 \omega t-75^{\circ}\right), \\
& \frac{1}{2} \times 1,216,000 \cos \left(2 \omega t-240^{\circ}-67.5^{\circ}\right), \\
& \frac{1}{2} \times 1,000,000 \cos \left(2 \omega t-4^{8} 0^{\circ}-60^{\circ}\right) .
\end{aligned}
$$

These form a closed triangle, notwithstanding the fact that the currents are unbalanced. triangle of currents shalf be closed, $\mathrm{I}_{b}^{\prime} \mathrm{O}$ must be greater than $I_{c}^{\prime} O$ by an amount $I_{b}^{\prime} I_{c}^{\prime}$, which shall be just equal and opposite to the current in the primary of the transformer in leg $A$, namely $I_{c}^{\prime} I_{b}^{\prime}$. Now the currents in the primaries of the transformers are directly proportional to the number of turns in the secondaries. Therefore the number of turns in the secondary of $B$ shall exceed that of $C$ by a number which shall be equal to the number of turns in the secondary of $A$. We therefore necessarily have two isosceles triangles. 
$\mathrm{O} e \mathrm{E}_{c}^{\prime}$ and $\mathrm{E}_{b}^{\prime} \mathrm{E}_{e}^{\prime}$, built up by the voltage vectors having the sides $O \mathrm{E}_{c}^{\prime}=\mathrm{O} e$ and $\mathrm{E}_{b}^{\prime} e \_\mathrm{E}_{b}^{\prime} \mathrm{E}^{\prime}$. The number of turns in the secondaries of the transformers (taking the primaries as $x, 000$ ) is most easily determined by taking the ratio of the sines of the angles in the triangles $\mathrm{I}_{c} \mathrm{I}_{c}^{\prime} \mathrm{I}_{b}^{\prime}$ and $\mathrm{O} i_{c} \mathrm{I}_{c}$, as follows :

$$
\begin{aligned}
& \frac{\mathrm{I}_{c}^{\prime} \mathrm{I}_{b}^{\prime}}{\mathrm{I}_{c}^{\prime} \mathrm{I}_{c}}=\frac{\sin 7.5^{\circ}}{\sin 60^{\circ}}=0.15 \mathrm{I}, \\
& i_{c} \mathrm{I}_{c}=\frac{\sin 52^{\circ} 5^{\circ}}{\sin 60^{\circ}}=0.915, \\
& i_{c} \mathrm{O}, \\
& \mathrm{I}_{b}^{\prime} \mathrm{O}=0.15 \mathrm{I}+0.915=\mathrm{I} .066 .
\end{aligned}
$$

Therefore the turns in the secondaries of $\mathrm{A}, \mathrm{B}$, and $C$, are $I_{5} I, I, 066$, and 915 respectively. With 1,000 volts on each of the three primaries of $I, 000$ turns we get :

$$
\begin{aligned}
\mathrm{E}_{c}^{\prime} \mathrm{O} & =9 \mathrm{I}_{5} \text { volts } \\
O \mathrm{E}_{b}^{\prime} & =\mathrm{I}, 066 \quad, \\
\mathrm{E}_{b}^{\prime} \mathrm{E}^{\prime} & =\mathrm{I}_{5} \mathrm{I} "
\end{aligned}
$$

and the vector sum of these is $E_{c}^{\prime} E^{\prime}=1,732$ volts, which gives us the voltage $e^{\prime}$ in the correct phase. If

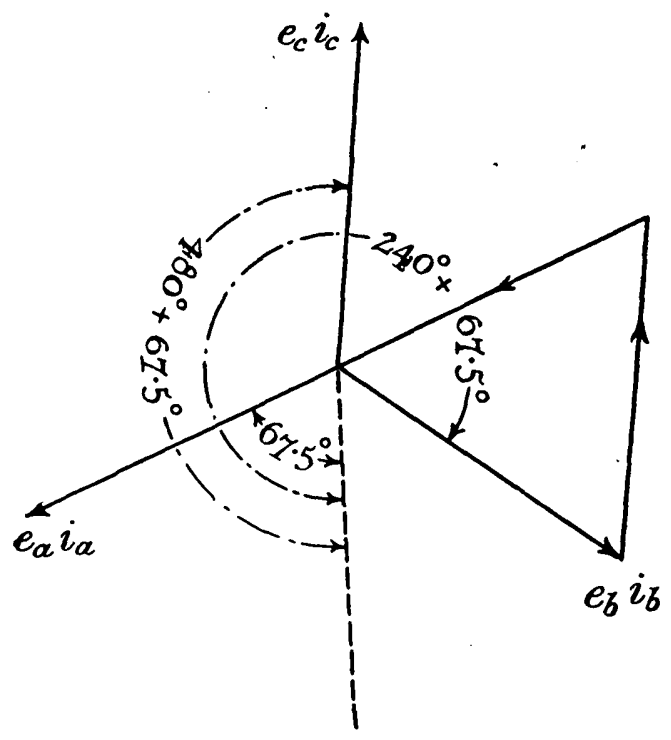

FIG. 38.

now we put in circuit with this a reactance of r.732 ohms we get 1,000 amperes lagging $90^{\circ}$ flowing in the secondaries, and this calls for currents in the primaries of the same phase (assuming perfect transformers) Ithe amounts of which are :

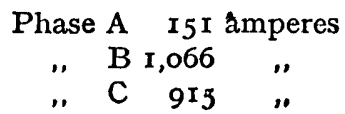

If now we add the $r, 000$ amperes $I_{S}$ in phase $A$ to $I_{c}^{\prime} I_{b}^{\prime}$, we get $I, 066$ amperes total in phase $A$; and if we add the $\mathrm{I}, 000$ amperes $\mathrm{O} i_{c}$ to $i_{c} \mathrm{I}_{c}$ we get $\mathrm{O} \mathrm{I}_{c}=\mathrm{I}, 066$, so that all three currents are equal and at $120^{\circ}$ to one another. The angle of lag of each current behind its E.M.F. is $67.5^{\circ}$ in each case. The alternating components of the power in the three circuits are equal, and the double-frequency vectors representing them are at $120^{\circ}$ to one another. They therefore cancel out (see Fig. 38).

\section{APPENDIX VI.}

Method of Choosing the Component Voltages from the Three Phases in Order to Build UP E' Sin $(\omega t-\beta)$, so as to Get Balanced Current in. THE CASE of a Condenser Balancer.

In this case $\beta=\frac{1}{2} \phi-\frac{1}{4} \pi=-22.5^{\circ}$; therefore $-\beta=+22.5^{\circ}$; so that in laying out $\mathrm{OE}^{\prime}$ in Fig. 40 we set off the angle at $22.5^{\circ}$ from $\mathrm{O} \mathrm{E}_{a c}$ anti-clockwise. The problem is to build up this voltage, $O E^{\prime}$, from the three-phase voltages $E_{a}, E_{b}$, and $E_{c}$. The scheme of connections is shown in Fig. 39. The condenser is fed from three secondaries connected in series, each secondary being wound on a separate core the primary of which is supplied from one of the three phases $A$, $B$, and $C$ respectively. It is assumed that there are $I, 000$ turns on each of the primaries; the problem is to find the number of turns on the secondaries so as to get the desired result.

The condenser current $\mathrm{I}^{\prime}$ (Fig. $4^{\circ}$ ) is $90^{\circ}$ ahead of $\mathrm{E}^{\prime}$, and is taken as 100 amperes, Ioo amperes being taken as the current on the single-phase furnace $I_{S}$. The value of the current in any one of the primaries of the transformers will be directly proportional to the number of turns of its secondary. It will be seen that the only current in phase $B$ will be the current fed to the primary of transformer $B$ (neglecting the magnetizing current); it will be in phase with $I^{\prime}$.

As we are aiming at having the resultant currents in phases $\mathrm{A}, \mathrm{B}$, and $\mathrm{C}$ at $120^{\circ}$ to one another, these currents must form the sides of an equilateral triangle such as that drawn in double lines in Fig. 40. The phase of the base of this triangle is given by the phase of $I^{\prime}$; and it will be further seen that the resultant A must be obtained by adding together the vector $\mathrm{O} \mathrm{I}_{S}$ and another vector parallel to $\mathrm{O} \mathrm{I}^{\prime}$; similarly, the resultant $C$ must be obtained by adding together the vector $\mathrm{O}-\mathrm{I}_{\mathrm{S}}$ and another vector parallel to $\mathrm{I}^{\prime} \mathrm{O}$. Thus the height of the equilateral triangle is determined by setting off a line $I_{S} I_{A}$ parallel to $O I^{\prime}$ and finding the point where it intersects the line $O I_{A}$, which is necessarily at $60^{\circ}$ to $O I^{\prime}$. The equilateral triangle is then completed by drawing the resultant $C$, which is necessarily equal to $\mathrm{OI}_{C}$ obtained by drawing a vector $-I_{S} I_{C}$ parallel to $I^{\prime} O$. If we now scale off the currents $I_{S} I_{A}, O I_{B}$, and $-I_{S} I_{C}$, we find that these are $11^{\circ} \cdot 44^{\circ}$, and 70 amperes respectively; 
therefore the number of turns in the secondaries of the transformers should be $I, 142,442$, and 700 respectively. If we now set off three voltage vectors $I_{1} I_{42}$,
The general method of calculation is that described by the author in his book "The Specification and Design of Dynamo-electric Machinery." In "torder

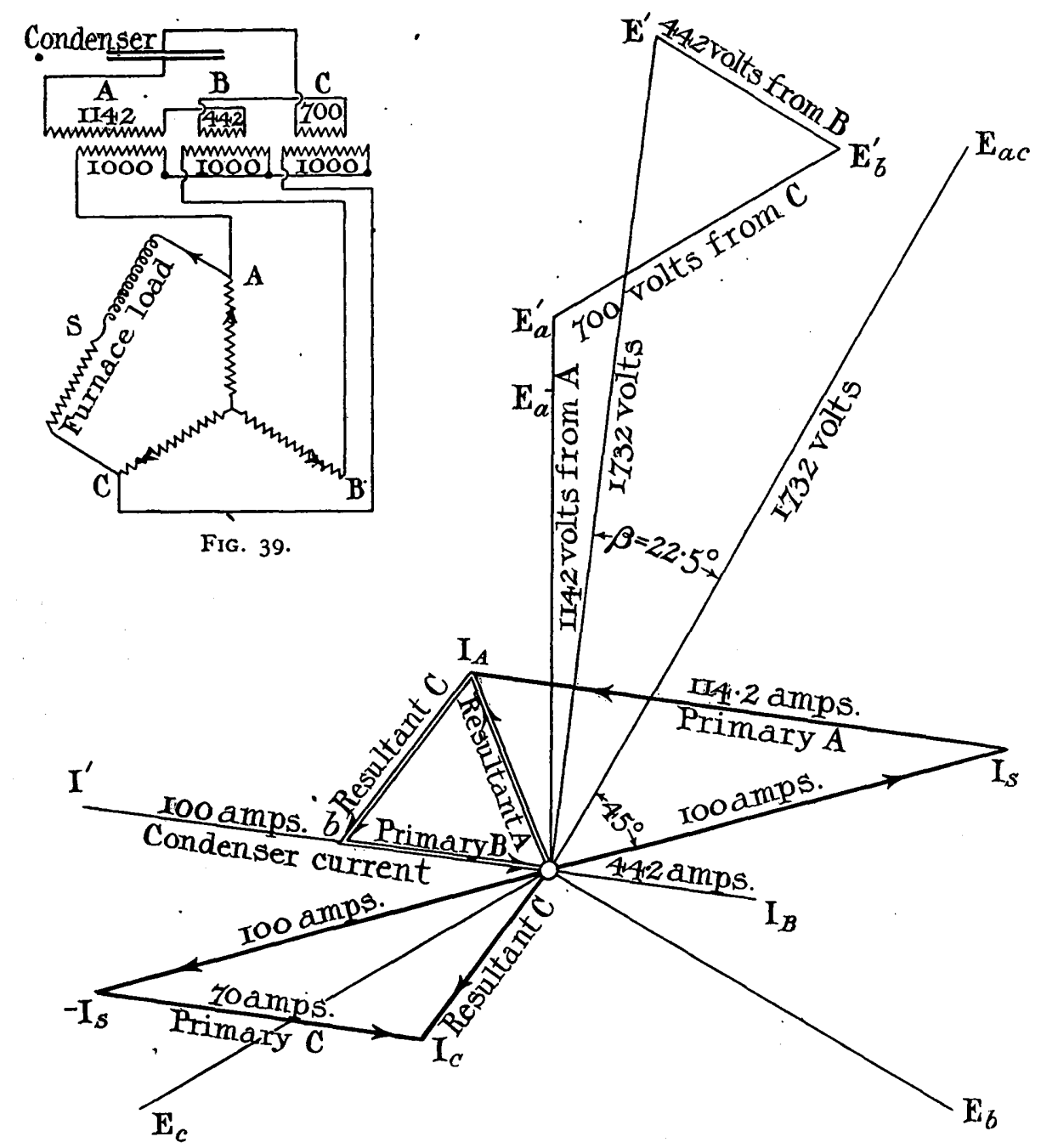

Frg. 40 .

70, and 442 volts respectively, parallel to $E_{a},-E_{c}$, and $E_{b}$ respectively, we obtain the vector $O E^{\prime}$ representing $I, 732$ volts, $22.5^{\circ}$ ahead in phase of $E_{a c}$.

\section{APPENDIX VII.}

\section{Calculation of Dimensions of the Machine.}

Size of frame and speed.-It was decided to use an 8-pole frame so as to get a speed of 750 r.p.m. Since single-phase machines require bigger frames than three-phase, a $\mathrm{D}^{2} l$ constant of $6 \times 10^{6}$ suggested a frame with an internal bore of $9 \mathrm{I}^{\circ} 5 \mathrm{~cm}$. and length of iron of about $42 \mathrm{~cm}$. The makers had a frame of size $140 \mathrm{~cm}$. (outside stator punchings), and as these figures appeared convenient they were decided upon. to shorten this paper, the author will rely upon the descriptions and explanations of the general method given in the book. The calculation sheet reproduced on page 124 is the same as that used throughout the book, see pages 317 to 320 . Matters that are rather special to this machine will be given somewhat more fully. All dimensions are given in centimetres.

Three-phase winding.-Allowing for impedance drop in the winding, the generated back E.M.F. should be about $6,000-60=5,940$ volts. As the frame would carry a total $\mathrm{A}_{g} \mathrm{~B}$ of about $\mathrm{I} \times 10^{8}$, an approximate number of conductors would be 1,200 . For 8 poles $\mathrm{I}, \mathrm{I}_{52}$ ( $=72$ slots $\times 16$ conductors per slot) is a convenient number. The E.M.F. coefficient $\mathrm{K}_{\epsilon}=\mathrm{O}_{4}$ (see page 23 of book). Reyolutions per second $=12.5$. We thus arrive at the voltage formula

$5,940=0 \% 4 \times 12.5 \times 1,152 \times 1 \cdot 03$. 
Size of three-phase conductors.-Allowing an efficiency of 90 per cent, we have $444 \mathrm{kw}$. input at unity power factor. This gives us 43 amperes per phase, or, allowing a little margin for power-factor adjustment, say 47 amperes per phase.

The size of conductor chosen was $0.26 \times 0.5 \quad(0.127$ sq. cm. in area, allowing for rounded corners). This gives $37^{\circ}$ amperes per square centimetre at 47 amperes. The 16 conductors are arranged in two rows of 8 , with substantial insulation between them.

In addition to the room taken up by 16 conductors per slot, room is left for 3 compensating conductors, the function of which is described on page 123 . These conductors were made $0.13 \times 1$, as they had not to be bent edgewise. The size of slot required was $\mathrm{I} \cdot 7 \mathrm{~cm}$. wide $\times 3^{\cdot} 7 \mathrm{~cm}$. deep. Particulars of the lengths and resistance are given in the calculation sheet.

Single-phase winding.-The single-phase winding is placed in $4^{8}$ slots at the back of the 48 slots occupied by phases A and C. No single-phase slots are punched behind the slots occupied by phase $B$. The shape of the punchings will be seen in Fig. $2 I$. Since a current of $2,75^{\circ}$ amperes would require a very large conductor, and since the single-phase voltage to be generated is very low, it is obviously the best plan to put 8 paths in parallel, each of which can contribute $2,750 / 8$ amperes. This gives us $34^{\circ}$ amperes per conductor, and at 50 cycles we should still be troubled with eddy currents if we did not split up the conductor for this current. The actual conductor chosen consists of 3 square wires in parallel. Each wire is $0.6 \mathrm{~cm}$. wide $(0.35 \mathrm{sq}$. $\mathrm{cm}$. in area). These individual wires are crossed over in the course of connecting up, so that each wire embraces exactly the same leakage flux, and no eddy currents flow between the three in parallel. The eddy currents in the individual wires lying in the slots, calculated by Field's curves, give a mean loss 22 per cent higher than the $I^{2} R$ loss for direct current.

The number of turns required in the single-phase winding to give 234 volts at no load can be calculated as in an ordinary transformer, so long as all wires are symmetrically placed with respect to the wires in the three-phase slots of phases $\mathrm{A}$ and $\mathrm{C}$, and have the same winding factor. In 48 slots we have $48 \times$ I $6=768$ conductors. $768 \times 234 \div 6,000=30$ conductors in 6 slots ( 5 turns per pole), or 5 conductors per single-phase slot. Had it been necessary to get 247 volts at no load, some of the three-phase conductors would have been cut out to increase the working flux by 5 per cent. Before the winding was completed, however, the makers of the furnace decided that they would not require more than 220 volts at no load, the relations between the various voltages on load being as indicated in Fig. 22. It was therefore necessary to cut out one of the I $_{5}$ turns per pole of the single-phase winding; and the question arose whether it should be a turn embracing 4 teeth or a turn embracing 8 teeth. To determine this, it is only necessary to calculate the winding factors* for the various singlephase coils and the winding factor for the three-phase winding in the 6 slots occupied by phases $A$ and $C$.
There being 9 slots per pole, the slot pitch is (electrically) $20^{\circ}$. None of the coils of the single-phase winding is of really full pitch. The largest coil, embracing 8 teeth, is short of full pitch by $20^{\circ}$; the second, by $60^{\circ}$; and the smallest coil, by $100^{\circ}$. Taking the winding factor of a really full-pitch coil to be unity', we have:

\begin{tabular}{|c|c|c|c|}
\hline \multirow{4}{*}{$\begin{array}{l}\quad \text { Coil } \\
\text { Longest } \\
\text { Middle } \\
\text { Smallest }\end{array}$} & & $\begin{array}{l}\text { Cosine of Half-angle of Phase- } \\
\text { difference of Coil Sides }\end{array}$ & $\begin{array}{l}\text { Phase- } \\
\text { les } \\
\text { les Winding } \\
\text { Factor }\end{array}$ \\
\hline & $\cdots$ & $\ldots \quad \cos 10^{\circ}$ & 0.9848 \\
\hline & . & $\cos 30^{\circ}$ & 0.866 \\
\hline & $\cdots$ & $\cos 5^{\circ}$ & 0.6428 \\
\hline
\end{tabular}

The mean winding factor can also be found by the formula given * by Smith and Boulding for coils lying in slots, namely:

$$
\frac{\sin \frac{1}{2} m \gamma}{m \sin \frac{1}{2} \gamma}=\frac{\sin 6 \times \frac{1}{2}\left(20^{\circ}\right)}{6 \sin \frac{1}{2}\left(20^{\circ}\right)}=\frac{\sin 60^{\circ}}{6 \sin 10^{\circ}}=0.831 \text {. }
$$

Now this winding factor, $0.83 \mathrm{I}$, applies to the threephase winding. Therefore, when we have 5,940 volts. (virtual) generated in the 768 conductors between the terminals $\mathrm{A}$ and $\mathrm{C}$, the volts per conductors generated are really :

$$
\frac{5,940}{768} \times \frac{I}{0.83 I}=9 \cdot 3 \text { volts (virtual). }
$$

We can arrive at the voltage generated by the 10 . conductors making up each coil, as follows:

Large coil .. $9.3 \times 0.9848 \times 10=91^{\prime} 7$ volts

Middle .. $9.3 \times 0.866 \times 10=805 \ldots$

Smallest .. $9.3 \times 0.6428 \times 10=59.8 \quad \ldots$

232 volts for 15 turns

If now we have only 4 turns (instead of 5 ) in the smallest coil, we get the figures as follows:

$$
\begin{aligned}
& \text { Large coil . . } \quad 9.17 \times 10=9 I^{\prime} 7 \text { volts } \\
& \text { Middle . 8 8.05 } \times 10=80^{\circ} 5 \text { ", } \\
& \text { Smallest . } 5.98 \times 8=47.8 \text {, } \\
& 220 \text { volts nearly, for } I_{4} \text { turns }
\end{aligned}
$$

Calculation of permeance of path for leakage flux and single-phase winding.-The amount of the reactive drop in the electric furnace and connections was not exactly known when the machine was first laid out. In order, therefore, to allow a margin for adjustment, the three-phase winding was arranged so that there might be either $\mathrm{r}_{5}$ wires per slot or $\mathrm{I} 6$ wires per slot, and the single-phase winding so that there might be I5 turns per pole, or any smaller number. With I5 wires per slot (instead of I6) in the three-phase winding, and 15 turns per pole in the single-phase winding, the open-circuit low-tension voltage would be $232 \times 16 / 15=247$. Even if the inductive drop in the furnace came out as high as 50 volts, it would still be possible to get the required output into the furnace

$$
\text { - Los, cit. }
$$


at this voltage by making the inductive drop in the single-phase winding about $\mathrm{I}_{4} \mathrm{O}$ volts. The total inductive drop would then be about 190 , and if the resistance drop were ${ }_{5} 6$ the right-angled triangle (see Fig. 4I) would be sufficiently well shaped for stable -aperation. If, however, the inductive drop in the furnace came out lower, the open-circuit voltage could 'be lowered either by using less than $I_{5}$ turns on the secondary or by increasing the wires in the threephase slots. These two expedients are somewhat different in their final effect. A reduction of the number of turns in the secondary is accompanied by a very considerable reduction in the inductance of the secondary winding, while an increase of the threephase conductors has very little effect upon the inductance. The depth and width of the air-gap in the leakage path between primary and secondary (see Fig. 2I) were adjusted to give about $\mathbf{I}_{40} \mathrm{O}$ volts inductive drop in the single-phase winding when the latter was carrying 340 virtual amperes in the $I_{5}$ turns per pole.

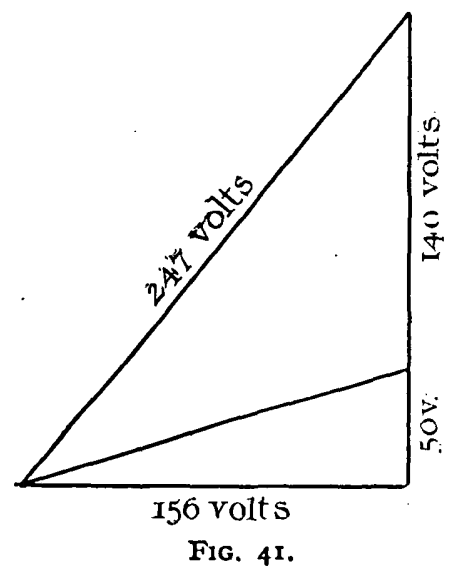

The main path for the leakage flux around the singlephase winding is that across the narrow slit $(0.45 \mathrm{~cm}$. wide) that has been provided for this purpose between the long teeth. The radial length of the slit and its width were determined by some such calculation as that given below, which takes into account the amount of leakage occurring across the three-phase slot, the single-phase slot, etc. All that was necessary was to see that the radial depth $(4.7 \mathrm{~cm}$.) was great enough to carry the balance of the leakage flux required. The following is the final calculation.

Permeance (per cm. length of iron) of the leakage path for flux produced by single-phase winding (see page 422 of author's book for explanation of the method of calculation).

Body of three-phase slot $3 \cdot 7 \div 1 \cdot 7 \quad \ldots=2 \cdot 2$

Mouth of slot $\ldots \quad \ldots \quad \ldots \quad \ldots=I \cdot r$

Zigzag $0.34 \times \frac{4}{2} \times \frac{1}{2 \times 0.55 \times 1 \cdot 1} \quad \cdots=0.56$

Leakage air-gap $4.7 \div 0.45 \quad \ldots \quad \ldots=10.4$

Compensating conductor space $\mathrm{I} \cdot \mathrm{I} \div \mathrm{I} \cdot 8=0.6 \mathrm{I}$

Single-phase slot $\frac{1}{3} \times \frac{3.8}{2.3} \quad \ldots \quad \ldots=\frac{0.55}{15.42}$
Twice the length of iron $\quad \ldots \quad \ldots=42 \times 2=84 \mathrm{~cm}$.

M.M.F. per slot $=34^{\circ} \times 5 \times \mathrm{I} \cdot 4 \mathrm{I} \times \mathrm{I} \cdot 257=3,020$

$$
\begin{aligned}
& 15.42 \times 84 \times 3,020 \quad \ldots \quad \ldots=3.92 \times 10^{6} \\
& \text { End leakage } \ldots \quad \ldots \quad \ldots=0.4 \times 10^{6} \\
& \text { Leakage lines per pole } \quad \ldots=4.32 \times 10^{6}
\end{aligned}
$$

As the reluctance of the magnetic path is mainly in the air-gaps considered, the leakage flux (when

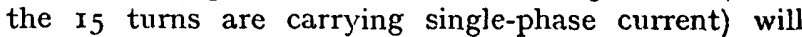
encircle all $\mathrm{I}_{5}$ conductors. The voltage generated will therefore be :

Reactance volts in single-phase winding

$$
\begin{aligned}
& =0.707 \times 2 \pi \times 50 \times 15 \times 4.32 \times 10^{-2} \\
& =144 \text { volts, or } 144 / 30=4.8 \text { volts per conductor. }
\end{aligned}
$$

This is with 15 turns per pole in the single-phase winding. If we reduce the number of conductors in one of the slots from 5 to 4 , we do not affect the leakage across the remaining slots, but we cut down the volts per conductor in the one slot to $4.8 \times 4 / 5$ $=3.85$ per conductor. The reactance voltage for 14 turns per pole is therefore $(20 \times 4.8)+(8 \times 3.85)$

$$
96+31=127
$$

It is better to have the reactance rather too little than rather too much, because if it is too much it is impossible to get the full input, whereas if it is too little one can always reduce the input by increasing the length of the arc. We shall therefore take the figure 127 volts as near enough to 128 volts (the theoretical value given by Fig. 22) for practical purposes, and we cannot hope to predetermine the leakage flux with any great degree of accuracy.

Taps on single-phase winding.-It is sometimes desirable, after the metal is heated up in a refining furnace, to reduce the electrical input to such a point that the metal is maintained at an even temperature for some time. For this purpose it is usual to provide means of reducing the voltage in the furnace to less than one-half. In this case it was decided to put a tapping in each group of coils in parallel, at a point 5 turns removed from the outer terminal. These five turns will give $9 \cdot 17 \times$ Io $=9 \mathrm{I} \cdot 7$ volts.

\section{APPENDIX VIII.}

Method of Calculating the Number of CompenSATING TURNS.

Below is given the calculation of the flux across I $\mathrm{cm}$. length of three-phase slot produced by unit magnetomotive force in the single-phase slot and effective in producing E.M.F. in the three-phase windings. It will be noted that the effective permeance of the body of the three-phase slot is taken at one-half the value taken above. This is for the reason that the conductors nearest the mouth of the 
three-phase slot do not embrace the whole of the flux. in question. The total cutting of lines may be taken approximately as one-half the flux into all the conductors. Deducting $0.3 \mathrm{~cm}$. for the insulation space at the top of the slot, the effective depth of slot is $3.4 \mathrm{~cm}$.

Half body of three-phase slot $\frac{1}{2} \times(3 \cdot 4 \div \mathrm{I} \cdot 7)=\mathrm{r} \cdot 0$ Mouth of slot $\quad . \quad \ldots \quad \ldots \quad \ldots=\mathbf{I} \cdot \mathbf{I}$ To rotor and back despite damper . . .

$$
\overline{2 \cdot 66}
$$

Flux threading through compensating winding per $\mathrm{cm}$. length of iron for unit M.M.F. in single-phase slot

$$
=2.66 \times 19=50.5 \text {. }
$$

Leakage air-gap $\quad \ldots \quad \ldots \quad \ldots \quad \ldots=10 \cdot 4$

Three-phase slot $3 \cdot 4 \div I \cdot 7 \quad \ldots \quad \ldots=2 \cdot 0$

Half compensating coil slot $=\frac{1}{2}(I \cdot I \div I \cdot 8)=0 \cdot 3$

$$
\text { I } 2 \cdot 7
$$

From this it appeared that four compensating conductors $\left(4 \times \mathrm{r}_{2} \cdot 7=50^{\circ} 8\right)$ would embrace as much leakage flux as 19 conductors in the three-phase slots. The original design provided for ${ }_{15}$ working conductors -per slot plus four compensating conductors. When, however, it was found that the reactive voltage of the furnace was only about 28 volts, it was necessary to increase the three-phase conductors to 16 . This cut down the compensating conductors from 4 to 3 . To make up for this deficiency, a slightly unsymmetrical connection (described above) was made in the bringing out of the connections to the star point. This had the effect of substantially balancing the phases at full load, as will be seen from the figures given on page 126 .

\section{APPENDIX IX}

\section{Calculation of the Ampere-turns on the} FIELD-MAGNET.

It is necessary to make a calculation of the number of ampere-turns required at full load in order to preserve unity power factor on the three-phase side.

Single-phase armature ampere-turns. - The power factor of the single-phase load is 0.7 , so that the demagnetizing effect of the single-phase winding will be considerable. The best way of estimating the single-phase reaction is to rely upon experience with previous machines. As shown above, the average magnetizing effect of a single-phase load may be taken as from 0.65 to 0.75 of the magnetizing effect of a load of the same current per phase on all three phases. On this machine we have a very effective damper, and may take the effect of the single-phase load as equivalent to about o.7 of the corresponding three-phase load. In the low-tension winding we have $\mathrm{r}_{4} / 3$ conductors per slot. The current per conductor is 340 : amperes. The singleVOL. 57. phase ampere-turns may therefore be taken as $\frac{14}{3} \times \frac{72 \times 340 \times 0.43 \times 0.7}{8}=4,280$ ampere-turns per pole.

Three-phase armature ampere-turns.-With 47 amperes per phase in the three-phase winding, the ampereturns per pole are $47 \times 1,152 \times 0.43 \div 8=2,900$ ampero turns per pole.

Inductive drop in three-phase winding.-The permeance of the armature leakage path for leakage flux generated by the three-phase current can be calculated as follows:

$$
\begin{array}{llll}
\text { Body of slot } \frac{1}{3} \times(3.4 \div \mathrm{I} \cdot 7) & \ldots=0.06 \\
\text { Mouth.. } & \ldots & \ldots & \ldots=\mathbf{1} \cdot 0 \\
\text { Zigzag } & \ldots & \ldots & \ldots=0.56 \\
& & &
\end{array}
$$

Leakage flux across slots at load of 47 amperes :

$2.22 \times 42 \times 2 \times 16 \times 1.4 \mathrm{I} \times 1.257 \times 47=0.25 \times 10^{6}$

End leakage.. $\quad . \quad \ldots \quad \ldots=0.15 \times 10^{6}$

$$
\text { . } \quad \overline{0.4 \times 10^{6}} \text { lines per }
$$

The working flux per pole $=8.6 \times 10^{6}$. pole.

Inductive drop in thręe-phase winding

$$
=\frac{0.4}{8.6} \times 6,000=280 \text { volts. }
$$

Resistance drop in three-phase winding.

Resistance per phase .. $=\frac{1}{3}(2 \cdot 34)=0.78 \mathrm{ohm}$. $0.78 \times 47 \times \mathrm{I} \cdot 73 \quad \ldots=64$ volts.

Resultant ampere-turns - We are now in a position to draw the vector diagram that shows the relation

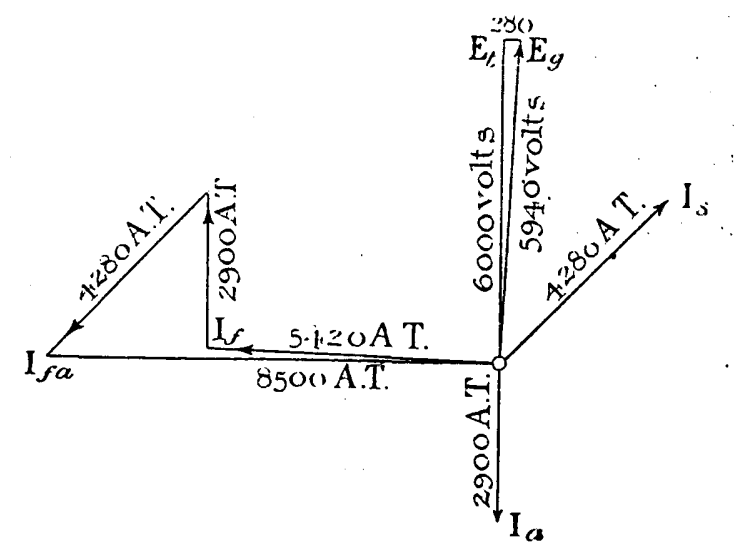

FIG. 42.

between the various magnetizing and demagnetizing ampere-turns on the field magnet and armature. This is given in Fig. 42 .

The conventions used in setting out this vector diagram are the same as those employed in Fig. 300 of the author's book referred to above. It "will be seen that the ampere turns of the armature are repre- 
sented by the line $I_{a}$, which is $180^{\circ}$ out of phase with the terminal voltage vector $E_{t}$. This is due to the fact that the machine is running as a synchronous motor on unity power factor. The single-phase armature ampere-turns $I_{S}$ are set off at $45^{\circ}$ behind $E_{t}$, because the single-phase armature is supplying a generator load at power factor 0.7 . From the calculation sheet we see that 5,420 effective ampere-turns are required on the field pole to generate $\mathrm{E}_{g}=5,940$ volts (obtained by setting off the impedance drop from the terminal volts $E_{t}$ ). The vector $I_{f}$ is set off to represent 5,420 ampere-turns to scale at right angles to $\mathrm{E}_{\mathrm{g}}$. Then, setting off $\mathrm{I}_{a}$ and $\mathrm{I}_{S}$ reversed we arrive at $\mathrm{I}_{f a}$, representing 8,500 ampere-turns to be applied to the field pole to neutralize the single-phase and three-phase armature reactions and leave 5,420 effective ampereturns to generate $\mathrm{E}_{\mathrm{g}}$. This graphic construction gives a result which agrees fairly well with the figures obtained on test. The exciting current required to give a mean power factor of unity (as will be seen later, the phases were not perfectly balanced) was 39 amperes; so that the applied field ampere-turns per pole were $39 \times 224=$ 8.736. The saturation of the poles may have been higher than expected, or the single-phase reaction rather more than 4,250 ampere-turns.

\section{APPENDIX $\mathrm{x}$.}

\section{Calculation of the Armature Copper losses.}

Single-phase coils.-The measured resistance of each of the 8 coils of $x_{4}$ turns in the single-phase winding is $0.00442 \mathrm{ohm}$ at $14^{\circ} \mathrm{C}$. The crossing over of the three wires in parallel that make up the conductors of these coils had the effect of preventing any violent eddy current in the conductor as a whole; but there is still a small eddy current, owing to the fact that each wire has a depth of $0.6 \mathrm{~cm}$. In the conductor lying nearest to the mouth of the slot, the eddy current, calculated from Ficld's curves, * gives rise to an additional loss equal to 55 per cent of the normal copper loss; so that $K_{d}=I^{\circ} 55$. The values of $K_{d}$ for all conductors are as follows:

$$
\begin{aligned}
& m_{1}=1 \cdot 0 \\
& m_{2}=1 \cdot 06 \\
& m_{3}=1 \cdot 17 \\
& m_{4}=1 \cdot 33 \\
& m_{3}=\mathrm{I} \cdot 55 \\
&=\overline{6 \cdot 1 \mathrm{I}} \\
& \mathrm{I} \cdot 22
\end{aligned}
$$

so that on the whole the eddy currents only increase the normal loss in the buried copper by 22 per cent. Allowing for a rise of resistance with temperature of 20 per cent, we have the normal loss (without eddies) in the 8 coils:

$0.00442 \times 1.20 \times 340 \times 340 \times 8=4,900$ watts.

- Transations of the Amorican Instibute of Electrical Engincers, 1905,
vol. 24, P. 761.
Of these, $(42 / 92) \times 4,900=2,240$ watts are in copper buried in the slots. This must be multiplied by $1 \cdot 22$ to allow for eddy currents:

$$
2,240 \times I \cdot 22=2,740 .
$$

The losses in the copper of the end windings would be normally 2,660 watts. This is also somewhat increased by eddy-current losses, though not to the samo extent as the copper in the slots. Allowing ro per cent increase due to eddies in the end windings, we get a total loss in the single-phase winding

$$
2,740+2,926=5,666 \text { watts. }
$$

Three-phase winding.-The hot resistance of the three-phase coils is 2.24 ohms. The loss for a current of 47 amperes is 4,950 watts.

Heat dissipated from the end windings.-The total cooling surface of the three-phase and single-phaso end windings is $86,000 \mathrm{sq}$. cm. In view of the strong. draught created by the blower, each square centimetre can easily get rid of 0.09 watt per sq. $\mathrm{cm}$. for 30 degrees $C$. rise of the outside of the coils. And as the half-length of the machine is only $21 \mathrm{~cm}$., one may expect quite a large percentagre of the heat generated in the slots to find its way to the end windings and pass into the air along with the heat generated in the end windings.

Total losses in three-phase and single-phase coils Io,6ro $86,000 \times 0.09$ $\begin{array}{rrrrrrr} & \cdots & \cdots & \cdots & \cdots & \cdots & \frac{7,740}{2,870}\end{array}$

Thus we have 2,870 watts to pass through the slot insulation to join the heat generated in the iron.

Iron losses.- The calculated iron loss at no load is. II,500. To this figure must be added very considerable stray losses at full load. These losses cannot be calculated, but they are estimated at 4.000 watts. Thus the total losses to be dissipated from the surfaces of the iron are about:

$$
\begin{array}{llllr}
\text { Iron loss } & \ldots & \ldots & \ldots & \mathbf{I 1 , 5 0 0} \\
\text { Stray losses } & \ldots & \ldots & \ldots & 4,000 \\
\text { Buried copper } & & \ldots & \ldots & 2,870 \\
& & & & 18,370
\end{array}
$$

The manner in which this loss can be dissipated from the surfaces of the stator for a temperature rise of 45 degrees $C$. is shown in the calculation given below. For further particulars of the method employed the author refers to his book (page 254).

Heat dissipated from working face of armature.-Peripheral speed 36 metres per second. Assuming a difference of temperature of 35 degrees C. between: iron and air, we have

$$
\begin{aligned}
& \text { Watts per sq. cm. }=\frac{35 \times(1+3 \cdot 6)}{333}=0.485 . \\
& 12,100 \text { sq. cm. } \times 0.485=5,900 \text { watts. }
\end{aligned}
$$


Heat dissipated by ventilating ducts. - Taking the coefficient $\mathrm{K}_{\mathbf{0}}=0.0007$ and the mean velocity in the ducts at 7 metres per sec., we have

$$
h_{0}=0.0007 \times 7=0.0049 \text {. }
$$

The total area of ventilating ducts, including the leakage air-gaps, is $83,600 \mathrm{sq}$. $\mathrm{cm}$. Taking the mean difference in temperature between the iron and air. in ducts at 20 degrees $C$., we have

$0.0049 \times 20 \times 83,600=8,200$ watts.

Heat dissipated from outside of stator.

38,700 sq. $\mathrm{cm} . \times 0 \cdot 1_{5}=5,800$.

Total heat dissipated from stator for 45 degrees $C$. rise. $5,900+8,200+5,800=19,900$ watts.

\section{SPECIFICATION OF 444-K.V.A. SYNCHRONOUS BALANCER THREE-PHASE TO SINGLE-PHASE.}

6,000 volts to 240 volts.

Reactive drop, $1_{4} 0$ volts.

50 cycles, 8 poles, $75^{\circ}$ revs. per minute.

Amperes per terminal : three-phase, 47 ; single-phase, 2,750 .

Stator.

(All dimensions in centimetres.)

\begin{tabular}{llll} 
Outside diameter & $\ldots$ & $\ldots$ & $\mathbf{I 4}^{\circ}$ \\
Inside diameter & $\ldots$ & $\ldots$ & $91 \cdot 5$ \\
Gross length & $\ldots$ & $\ldots$ & $4^{2}$ \\
Air vents $6 \times 0 \cdot 7=$ & $\ldots$ & $\ldots$ & $4^{\cdot 2}$ \\
Net length of iron & $\ldots$ &. & 34 \\
Depth below slots & $\ldots$ & $\ldots$ & I0 \\
\multicolumn{2}{c}{ Stalloy iron. }
\end{tabular}

72 three-phase slots each $1 \cdot 7 \times 4 \cdot x$ (see Fig. 21 ).
Three-phase winding.-- 16 effective conductors per slot. Room in slot for 19 conductors. Phases A and $C$ have 19 conductors per slot, three of them forming part of compensating winding. Phase $B$ has 16 conductors per slot. Size of conductors $0.26 \times 0.5$. Three taps to be brought out of each phase near the star point, viz. at 3, 6 and 9 turns respectively from the star point.

Single-phase winding, lying in 6 slots per pole, as shown in lay-out. 5 conductors per slot, each consisting of 3 square wires in parallel. Size of wire 0.6 $\mathrm{cm}$. square $(=0.35 \mathrm{sq} . \mathrm{cm}$.$) . I 5$ turns per pole, 8 poles in parallel. The 3 individual wires are to be crossed over by special connectors at the joints One tapping to be brought out of each coil.

\section{Field Magnets. \\ 8 poles.}

Pole-body, $16.5 \times 35$. Soft iron or very mild steel.

Pole arc, 24. Rarial length of gap, 0.5 .

Radius of curvature of pole face, $4 \mathbf{I} \cdot 3$.

Bevel extending over $3 \mathrm{~cm}$., giving an, air-gap at corner of 0.8 .

Field winding.-224 $(32 \times 7$ layers $)$ turns per coil. Size of wire, $0.35 \times 0.35$ (say. No. 10 B.W.G. square wire). Exciting current 40 amperes, 50 volts.

Dimper.-I I bars per pole, 9 drawn taper bars about $\mathbf{I} \cdot 3$ sq. $\mathrm{cm}$. section. End rings each built up in 8 sections, one section per pole, bolted together, crosssection about 7.5 sq. $\mathrm{cm}$. Damper rods held in dovetail grooves machined out of pole face: these are preferably skewed over the pitch of slots.

Poles should be laminated.

\section{Discussion before The Institution, 5 December, rgi8.}

Dr.S.P. Smith: Only those who have tackled problems like those considered in the present paper will appreciate the amount of labour involved, but the interesting and useful solutions often obtained may well repay the investigator, and students should not be discouraged purposes of illustration. The connections of this furnace are shown in Fig. A, and the problem considered here is to arrange the number of turns in the secondary winding of the transformer in such a manner that the load on the primary side is balanced when

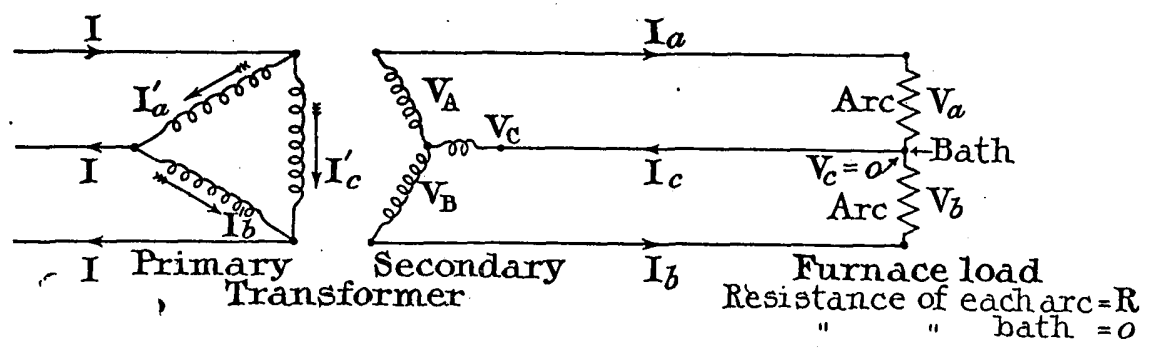

. FIG. A.

by the inherent difficulty of the subject. The author's use of vectors for solving these problems reminds me of the interesting case offered by the Greaves-Etchells two-arc furnace. The fact that it is not a single-phase furnace does not make the problem less useful for the the resistance of the load phase formed by the hearth of the furnace is zero. At first sight it would seem that a load of this nature on the secondary side would cause the load on the primary side to be unbalancerl. The vector diagram in Fig. B. however, shows that 